\title{
c-Abl inhibits breast cancer tumorigenesis through reactivation of p53-mediated p21 expression
}

\author{
Chevaun D. Morrison ${ }^{1, *}$, Tressa M. Allington ${ }^{2, *}$, Cheryl L. Thompson ${ }^{3}$, Hannah L. \\ Gilmore ${ }^{4}$, Jenny C. Chang ${ }^{5}$, Ruth A. Keri ${ }^{6}$, William P. Schiemann ${ }^{1}$ \\ ${ }^{1}$ Case Comprehensive Cancer Center, Case Western Reserve University, Cleveland, OH 44106, USA \\ ${ }^{2}$ Department of Pharmacology, Anschutz Medical Campus, University of Colorado-Denver, Aurora, CO 80045, USA \\ ${ }^{3}$ Department of Nutrition, Case Western Reserve University, Cleveland, OH 44106, USA \\ ${ }^{4}$ Department of Pathology, University Hospitals, Case Medical Center and Case Western Reserve University, Cleveland, \\ $\mathrm{OH} 44106$, USA \\ ${ }^{5}$ Houston Methodist Research Center, Houston, TX 77030, USA \\ ${ }^{6}$ Department of Pharmacology, Case Western Reserve University, Cleveland, OH 44106, USA \\ *These authors contributed equally to this work \\ Correspondence to: William P. Schiemann, email: william.schiemann@case.edu
}

Keywords: breast cancer, $c-A b l, p 53$, transforming growth factor- $\beta$, triple-negative breast cancer

Received: January 20, $2016 \quad$ Accepted: September 02, $2016 \quad$ Published: September 08,2016

\section{ABSTRACT}

We previously reported that constitutive c-Abl activity (CST-AbI) abrogates the tumorigenicity of triple-negative breast cancer cells through the combined actions of two cellular events: downregulated matrix metalloproteinase (MMP) and upregulated p21 $1^{\text {Waf1/cip1 }}$ expression. We now find decreased c-Abl expression to be significantly associated with diminished relapse-fee survival in breast cancer patients, particularly those exhibiting invasive and basal phenotypes. Moreover, CST-Abl expression enabled 4T1 cells to persist innocuously in the mammary glands of mice, doing so by exhausting their supply of cancer stem cells. Restoring MMP-9 expression and activity in CST-Abl-expressing 4T1 cells failed to rescue their malignant phenotypes; however, rendering these same cells deficient in p21 expression not only delayed their acquisition of senescent phenotypes, but also partially restored their tumorigenicity in mice. Although 4T1 cells lacked detectable expression of p53, those engineered to express CST-Abl exhibited robust production and secretion of TGF- $\beta 1$ that engendered the reactivated expression of p53. Mechanistically, TGF- $\beta$-mediated p53 expression transpired through the combined actions of Smad1/5/8 and Smad2, leading to the dramatic upregulation of p21 and its stimulation of TNBC senescence. Collectively, we identified a novel c-Abl:p53:p21 signaling axis that functions as a powerful suppressor of mammary tumorigenesis and metastatic progression.

\section{INTRODUCTION}

c-Abl is a multifunctional nonreceptor protein tyrosine kinase that regulates the physiology and homeostasis of normal mammary epithelial cells (MECs). However, controversies exist as to the exact role played by c-Abl during the development and progression of solid tumors, including those of the breast. Indeed, several reports have characterized $\mathrm{c}-\mathrm{Abl}$ as an oncogene that mediates enhanced survival and motility of breast cancer cells [1-9]. In contrast, c-Abl expression and activity are strongly associated with guarding and maintaining the integrity of the genome, doing so through its ability to induce cell cycle arrest and apoptosis in response to DNA damage [10-13]. As such, c-Abl is also implicated as being a powerful suppressor of breast cancer tumorigenicity both in vitro and in vivo [3, 14-16]. Recent clinical trials designed to assess the effectiveness of the c-Abl inhibitor, Imatinib, which revolutionized the treatment and clinical outcomes for patients with chronic myelogenous leukemia (CML) $[17,18]$, failed to provide similar benefits in breast cancer patients, many of whom 
experienced significant toxicity and disease progression in response to Imatinib administration [19-21]. Thus, the functions of c-Abl in normal and malignant MECs are complex and may vary across distinct breast cancer subtypes that possess unique genetic and epigenetic backgrounds.

Transforming growth factor- $\beta$ (TGF- $\beta$ ) is a multifunctional cytokine that suppresses mammary tumorigenesis by inhibiting cell cycle progression, or by stimulating programmed cell death. Interestingly, latestage breast cancers, including triple-negative breast cancers (TNBCs), become insensitive to the tumor suppressing activities of TGF- $\beta$, and instead readily exhibit epithelial-mesenchymal transition (EMT), invasive, and metastatic phenotypes in response to TGF- $\beta$ [22]. The acquisition of oncogenic activity by TGF- $\beta$ largely reflects imbalances between its canonical (i.e., Smad2/3dependent) and noncanonical (i.e., Smad2/3-independent) signaling systems [23]. Additionally, the presence of a TGF- $\beta$ gene signature predicts for poor clinical outcomes in TNBCs patients [24], whose tumors lack expression of estrogen receptor- $\alpha$, progesterone receptor, and ErbB2/ HER2, and exhibit high rates of metastasis and disease recurrence $[25,26]$. We previously identified c-Abl as a potent suppressor of TNBC tumorigenicity, as well as an inhibitor of oncogenic TGF- $\beta$ signaling [27]. Indeed, introducing a constitutively-active c-Abl (CST-Abl) mutant into murine TNBCs abrogated their expression of matrix metalloproteinases (MMPs), while simultaneously stimulating that of p21Waf1/Cip1 [27]. Unfortunately, the extent to which either pathway alleviates TNBC tumorigenicity following $\mathrm{c}-\mathrm{Abl}$ activation remains unknown, as does the role of TGF- $\beta$ in mediating these events. The goal of this study was to address these important questions and to determine how the c-Abl and TGF- $\beta$ signaling systems coalesce to elicit senescent phenotypes in TNBCs.

\section{RESULTS}

\section{Significantly reduced c-Abl expression associates with the progression of human breast cancers}

We previously demonstrated that constitutive c-Abl activity was sufficient to inhibit oncogenic TGF- $\beta$ signaling and its stimulation of EMT programs in normal and malignant MECs, as well as alleviate TNBC tumor development and metastasis in mice [27]. Additionally, Imatinib administration was ineffective and trended to enhance TNBC tumor growth in preclinical therapy trials in mice, findings reminiscent of those measured in metastatic breast cancer patients treated with Imatinib [27]. The notion that c-Abl functions as a suppressor of mammary tumorigenesis is further supported by the findings presented in Figure 1A, which shows c-Abl transcripts to be significantly downregulated in $\sim 70 \%$ of breast cancers. Likewise, interrogating the SAGE Genie tool housed within the Cancer Genome Array Project (http://cgap.nci.nih.gov) showed c-Abl expression to be most dramatically downregulated in breast cancers as compared to tumors arising in other tissues (Supplementary Table S1). Along these lines, Oncomine analyses of the Finak [28] and Richardson [29] datasets demonstrated dramatic reductions of c-Abl expression in invasive carcinomas (Figure 1B), and especially in basallike breast cancers as compared to their non-basal-like and normal counterparts (Figure 1C). Finally, interrogating the Kaplan-Meier Plotter database (http://kmplot/ analysis.com) showed that diminished c-Abl expression is significantly associated with reduced relapse-free survival in luminal A (Figure 1D) and basal-like (Figure 1E) breast cancers. Taken together, these findings reinforce the concept that c-Abl expression and activity suppresses mammary tumorigenesis.

\section{Enforced c-Abl activation enables TNBCs to persist innocuously in the mammary glands of mice}

Our previous study demonstrated that CST-Abl expression not only inhibited the oncogenic activities of TGF- $\beta$, but also induced a mesenchymal-epithelial transition (MET) in 4T1 cells that coincided with their loss of malignant behaviors [27]. Based on these findings, we hypothesized that the ability of CST-Abl to morphologically and phenotypically normalize 4T1 cells would enable them to reconstitute mammary gland morphogenesis following their transplantation into surgically cleared mammary fat pads of virgin female Balb/C mice. As noted previously [27], mice inoculated with parental 4T1 cells $(300,000$ cells/mouse) rapidly succumbed to lethal tumor burdens within 7 days (data not shown), while engrafting those that expressed CST$\mathrm{Abl}$ exhibited no overt signs of mammary tumorigenesis and readily survived for 8 weeks, at which point they were euthanized to facilitate the surgical excision of experimental mammary glands. Contrary to our expectations, the MET program initiated by CSTAbl failed to enable 4T1 cells to reconstitute normal mammary gland morphogenesis in mice, despite the fact that CST-Abl cells readily persisted within the transplanted fat pad as detected by GFP fluorescence and immunohistochemistry (Figure 2A, 2B). The inability of CST-Abl-expressing 4T1 cells to elicit tumor formation (Figure 2; [27]) and mammary gland reconstitution in mice suggested that CST-Abl may inhibit the "stemness" of 4T1 cells. Accordingly, CST-Abl expression abrogated 4T1 cell mammosphere formation (Figure 2C, 2D). Interestingly, induced pluripotent stem cells (iPSCs) can be generated through the simultaneous and enforced expression of Sox2, Klf4, Oct4, and Myc [30], an event coupled to the initiation of MET programs and 
suppression of EMT stimulated by TGF- $\beta$ [31]. These events are reminiscent of those attributed to CST-Abl in normal and malignant MECs (Figure 2; [27, 32]). As such, we monitored the effects of CST-Abl in altering Sox 2 and Klf4 expression in normal NMuMG and metastatic 4T1 cells. In doing so, we observed Sox 2 and Klf4 expression to be significantly downregulated in NMuMG and 4T1 cells following their acquisition of TGF- $\beta$-mediated EMT phenotypes (Figure 2E). In stark contrast and consistent with its role as an inducer of MET programs, we observed CST-Abl-expressing 4T1 cells to robustly elevate Sox2 and Klf4 transcript expression when stimulated by TGF- $\beta$ (Figure 2E). Collectively, these findings and those presented previously [27] demonstrate that the anticancer activities associated with CST-Abl expression are mediated in part via the induction of MET programs, which alleviate the cancer-initiating properties of TNBCs.

\section{A}
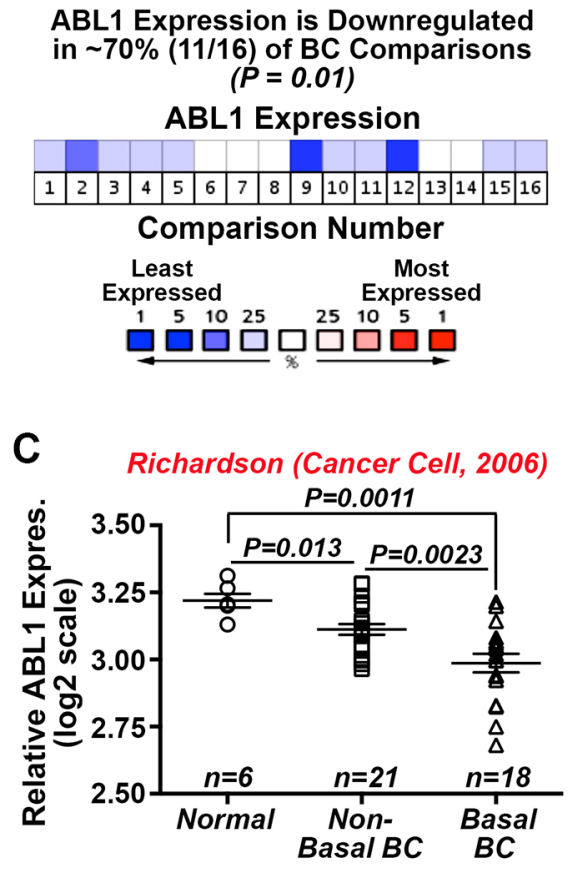

\section{Restoring MMP-9 expression and activity in CST-Abl-expressing 4T1 cells fails to rescue their tumorigenicity}

TGF- $\beta$ stimulates breast cancer cells to upregulate MMP expression, particularly that of MMPs 2, 3, and 9 [33], which enhance breast cancer invasion and metastasis $[34,35]$. We previously observed (i) CST-Abl to prevent TGF- $\beta$-mediated expression of MMPs 3, 9, and 13 in 4T1 cells [27], and (ii) MMP inhibitors to suppress the growth of 4T1 organoids in 3D-cultures [27, 36]. As such, we hypothesized that reinstating MMP-9 expression and activity in CST-Abl-expressing 4T1 cells would circumvent the antitumor activities mediated by CST-Abl and, consequently, restore their tumorigenicity. To test this hypothesis, we engineered parental and CST-Ablexpressing 4T1 cells to express an autoactivating MMP-9
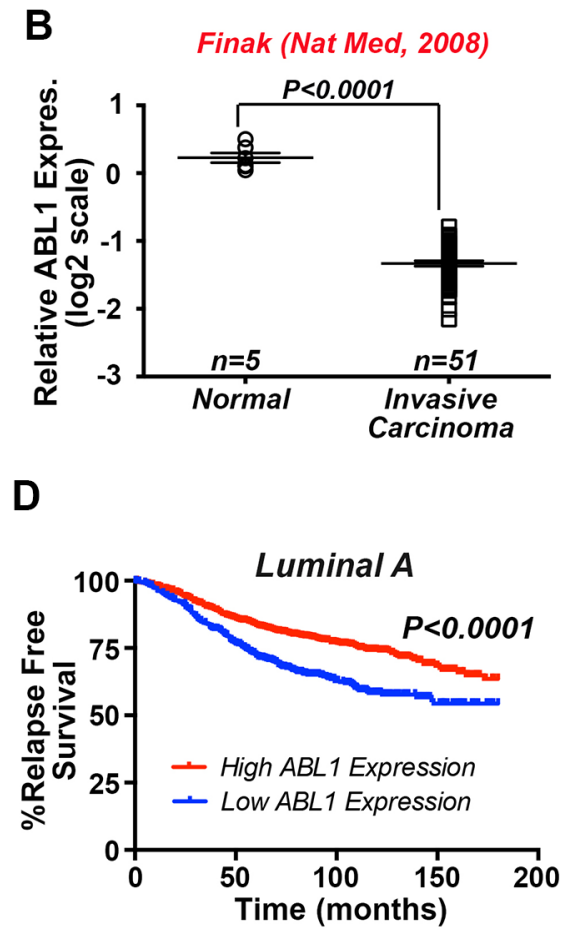

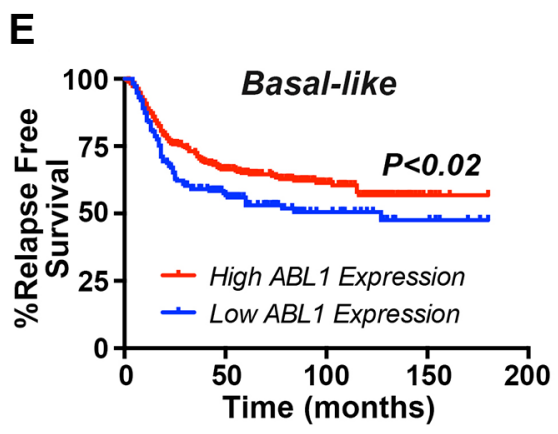

Figure 1: Significantly reduced c-Abl expression associates with the progression of human breast cancers. (A) Oncomine in silico analyses demonstrate that $A B L 1$ mRNA expression is significantly downregulated in 11 out of 16 study comparisons ( $70 \%$; $P=0.01$ ), including the Finak [28] (B) and Richardson [29] (C). (D and E) Kaplan-Meier plots correlating $A B L 1$ mRNA expression and the probability of relapse-free survival over 15 years in a cohort of 1678 luminal A (D) and 478 basal-like (E) breast cancer patients. 
mutant (i.e., G100L-MMP-9; [37]), as well as rendered parental 4T1 cells deficient in MMP-9 expression by their transduction with a lentiviral shRNA against MMP9 (Supplementary Figure S1A, 1B). In doing so, we found MMP-9-deficiency to significantly inhibit 4T1 cell proliferation (Supplementary Figure S1C) and invasion to a serum-stimulus (Supplementary Figure S1D); however, this same cellular condition had no effect on the ability of TGF- $\beta$ to induce 4T1 cell invasion (Supplementary Figure S1D). Interestingly, although the expression of G100L-MMP-9 mutants in CST-Abl-expressing 4T1 cells partially restored their invasiveness to serum, the proteinase activity of this MMP-9 mutant had no effect on TGF- $\beta$-stimulated invasion (Supplementary Figure S1E). Along these lines, manipulating the expression and activity of MMP-9 in parental and CST-Abl-expressing 4T1 cells had little-to-no impact on the resultant morphologies exhibited by these cells when propagated in compliant and rigid (i.e., collagen supplementation) 3D-cultures (Supplementary Figure S2). Finally, whereas MMP-9-deficiency significantly enhanced the growth of 4T1 tumors in Balb/C mice, we failed to detect any tumors

A
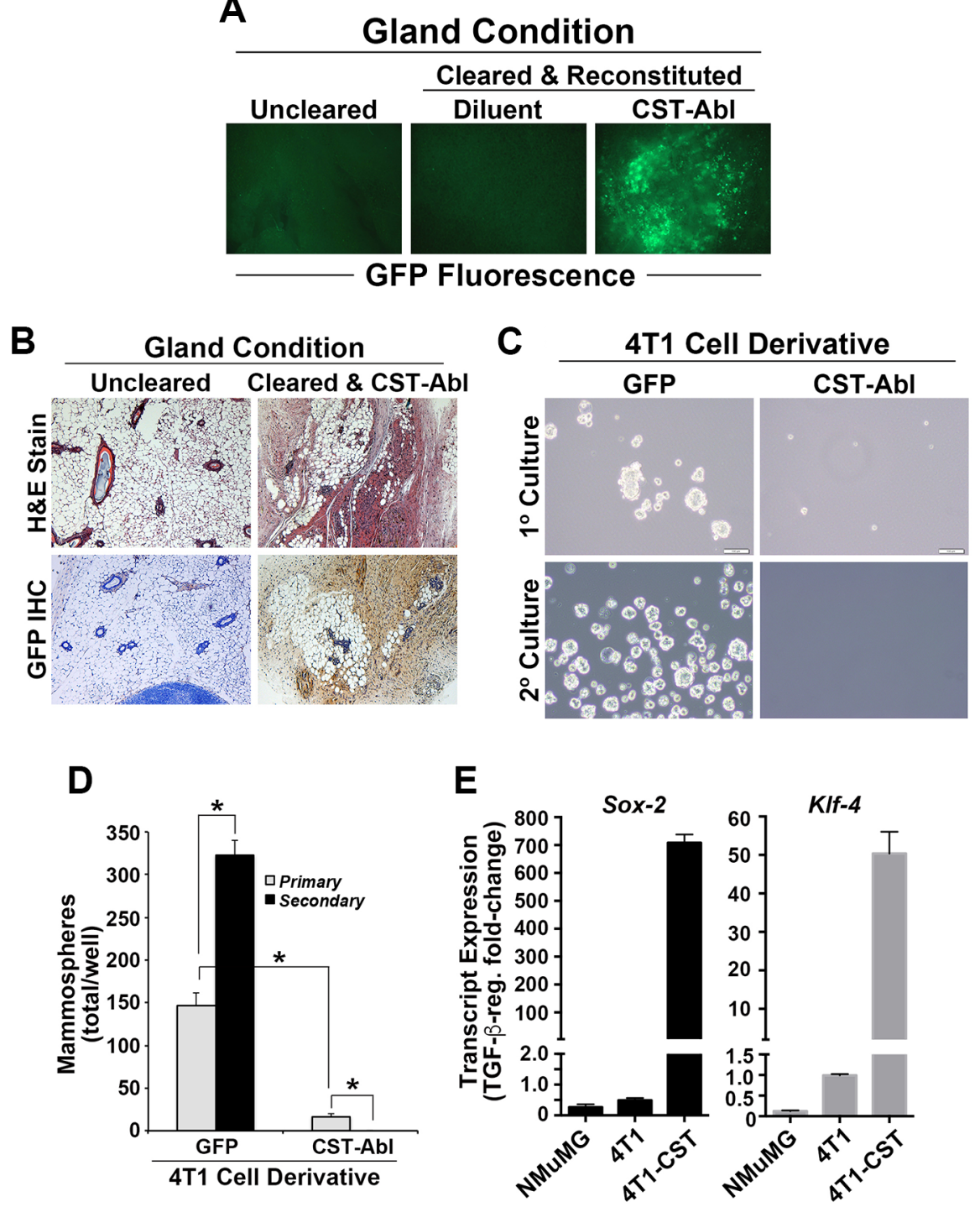

Figure 2: Enforced c-Abl activation enables TNBCs to persist innocuously in the mammary glands of mice. (A) Wholemount GFP fluorescence microscopy of mammary glands harvested from right inguinal \#4 mammary gland controls, and from cleared left \#4 inguinal mammary glands reconstituted with diluent (PBS) or CST-Abl-expressing 4T1 cells as shown. (B) H\&E (top) and antiGFP IHC (bottom) staining of recovered mammary glands demonstrates that CST-Abl-expressing 4T1 cells persisted innocuously in cleared mammary glands. (C and D) Parental (i.e., GFP) and CST-Abl-expressing 4T1 cells were cultured in ultra-low attachment plates to assess the formation of primary (day 7) and secondary (day 14) mammospheres. Representative photomicrographs from 3 independent experiments are provided $(\mathrm{C})$, as is the mean $( \pm \mathrm{SE})$ number of mammospheres produced by these analyses $(\mathrm{D}) .{ }^{*} P<0.05$. (E) NMuMG, parental 4T1 (i.e., GFP), and CST-Abl-expressing 4T1 cells were incubated in the absence or presence of TGF- $\beta 1$ (5 ng/ml) for $24 \mathrm{~h}$, at which point alterations in the expression of Sox-2 and $K l f-4$ were determined by semi-quantitative real-time PCR. Data are the mean ( \pm SE) fold-change in gene expression regulated by TGF- $\beta$ in 3 independent experiments. 
in mice engrafted with CST-Abl-expressing 4T1 cells that also expressed G100L-MMP-9 mutants (Supplementary Figure S3). Thus, while MMP-9 activity may regulate autocrine TGF- $\beta$ activity in 4T1 cells (Supplementary Figures S1-S3), the enforced expression and activation of this extracellular protease was unable to circumvent the tumor suppressing functions of CST-Abl in aggressive TNBCs.

\section{p21 ${ }^{\text {Waf1/Cip1 }}$ expression is required for morphological normalization and cytostasis driven by CST-Abl}

$\mathrm{p} 21^{\mathrm{Waf} 1 / \mathrm{Cip} 1}$ is a potent tumor suppressor that prevents uncontrolled cell proliferation by inducing cell cycle arrest, and stimulating cell differentiation. p21 expression is regulated by various factors and pathways, including several anticancer agents (e.g., statins and HDAC inhibitors), DNA damage, p53 and p73, oxidative stress, cytokines and growth factors, and TGF- $\beta$ [38-40]. Interestingly, p21 expression has also been linked to the acquisition of senescence phenotypes in breast cancer cells [41]. Because p21 is a major downstream effector of c-Abl in 4T1 cells [27], we next addressed the role of p21 in mediating the anticancer activities CST-Abl in normal and malignant MECs. In doing so, we transduced normal NMuMG, parental 4T1, and CST-Abl-expressing 4T1 cells with lentiviral shRNA particles to deplete their expression of p21 mRNA (Figure 3A) and protein (Figure 3B). Functionally, p21-deficiency markedly increased the magnitude of DNA synthesis in all three cell lines when propagated in 2D-cultures (Figure 3C, 3D), as well as uncoupled TGF- $\beta$ from regulating cytostasis in NMuMG cells (Supplementary Figure S4A). In addition, we previously noted that the enforced expression of CSTAbl in NMuMG cells arrests their proliferation after 2-4 divisions in 3D-cultures, and that parental and CSTAbl-expressing NMuMG cells apoptose when stimulated by TGF- $\beta$ in rigid 3D-cultures [27]. Supplementary Figure S4B, S4C shows that p21-deficiency also significantly enhanced the basal proliferation rate of NMuMG cells propagated under either compliant or rigid conditions, and that p21-deficient NMuMG cells were strikingly resistant to TGF- $\beta$-mediated apoptosis under these same cellular conditions. The enhanced resistance to apoptosis mediated by p21-deficiency did not appear to reflect differences in NMuMG cell "stemness" as parental and p21-deficient NMuMG cells exhibited similar defects in mammosphere maintenance (Supplementary Figure S5A). Thus, these findings suggest that the loss of p21 expression may confer normal MECs the ability to survive the tumor suppressing activities of TGF- $\beta$, thereby contributing to their eventual transformation.

Although 4T1 cells are insensitive to the antiproliferative activities of TGF- $\beta$ in traditional 2D-cultures (Figure 3C), we previously demonstrated that propagating these TNBCs in compliant 3D-cultures partially restores their cytostatic response to TGF- $\beta$, an event that is lost by culturing $4 \mathrm{~T} 1$ cells in mechanically rigid $3 \mathrm{D}$-cultures [27, 42]. Morphologically, CST-Abl-expressing 4T1 cells form small spherical and partially hollowed organoids in compliant 3D-cultures, which contrasted sharply with the large irregular organoid structures formed by their parental counterparts under identical culture conditions [27]. As expected, TGF- $\beta$ inhibited the growth of 4T1 organoids in compliant 3D-cultures, but readily stimulated their proliferation in rigid 3D-cultures (Figure 3E, 3F). Interestingly, p21-deficiency significantly enhanced the proliferation of parental and CST-Ablexpressing 4T1 organoids in both compliant and rigid 3D-cultures (Figure 3E-3H). As noted previously [27], CST-Abl expression restores the cytostatic activities of TGF- $\beta$ under both compliant and rigid 3D-culture conditions, a reaction that now appears to be partially dependent upon p21 expression (Figure 3C, 3D). Similar to NMuMG cells, the discrepancies in 4T1 cell behavior resulting from $\mathrm{p} 21$-deficiency did not reflect differences in the ability of parental and p21-deficient 4T1 cells to form mammospheres (Supplementary Figure S5B). Interestingly, introducing CST-Abl into 4T1 cells dramatically inhibited their ability to produce and maintain mammospheres when serially passaged. Moreover, Supplementary Figure S5B also shows that p21-deficient CST-Abl-expressing 4T1 cells initially enhanced their production of primary mammospheres, which were subsequently exhausted through serial passages. Collectively, these findings indicate that the induction of p21 expression by CST-Abl (Figure 3A; [27]) plays an essential role in suppressing TNBC growth, doing so in part by altering their self-renewal capacity.

\section{CST-Abl governs the coupling of TGF- $\beta$ to the activation of Smad2/3 and Smad1/5/8 in 4T1 cells}

Findings presented in Figures 2 and 3 suggest that CST-Abl inhibits oncogenic TGF- $\beta$ signaling; they also point to the intriguing possibility that this event may in fact be reliant upon signaling inputs derived from TGF- $\beta$ receptors. In addressing this hypothesis, we initially measured the concentrations of TGF- $\beta 1$ produced by parental and CSTAbl-expressing 4T1 cells. As shown in Figure 4A, CST$\mathrm{Abl}$ expression significantly increased the production and secretion of TGF- $\beta 1$, leading to augmented TGF- $\beta$ signaling as well (Figure 4B). Interestingly, although TGF- $\beta$ readily stimulated Smad 2 and Smad3 in 4T1 cells, we only detected the activation of Smad2 in CST-Abl-expressing 4T1 cells treated with TGF- $\beta$ (Figure 4C). In light of recent findings demonstrating crosstalk between BMP- and TGF- $\beta$ regulated Smads [43-45], we next determined whether CST$\mathrm{Abl}$ expression influenced the coupling of TGF- $\beta$ to classical BMP-regulated responses. Interestingly, although TGF- $\beta$ could indeed stimulate the phosphorylation of Smad1/5/8, 
this event only transpired in CST-Abl-expressing 4T1 cells and was readily inhibited by administration of the T $\beta \mathrm{R}-1 /$ ALK-5 inhibitor, SB431542 (Figure 4D). Likewise, the ability of TGF- $\beta$ to activate a BMP-responsive reporter gene (i.e., BRE-luciferase) was also specific to CSTAbl-expressing 4T1 cells (data not shown). Finally, we asked whether the TGF- $\beta$-dependent increase in Smad1/5/8 phosphorylation in CST-Abl expressing 4T1 cells was dependent upon the activity of the BMPR1A.
Figure 4E shows that TGF- $\beta$ stimulation of Smad1/5/8 phosphorylation was unaffected by administration of the BMP antagonist, BMPR1A (ALK1-FC), which robustly inhibited the coupling of BMP2 to Smad1/5/8 phosphorylation and BRE-driven luciferase expression (data not shown). Collectively, these findings demonstrate that the coupling of TGF- $\beta$ to Smad1/5/8 was dependent upon the activities of c-Abl and T $\beta R I$, and conversely, were independent of BMP type I receptors.
A
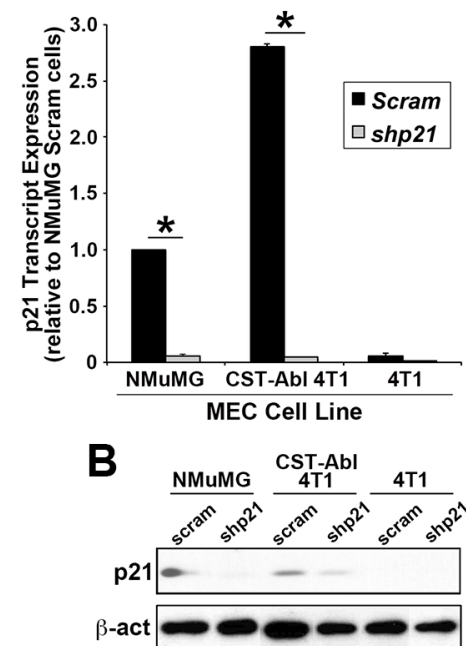

C

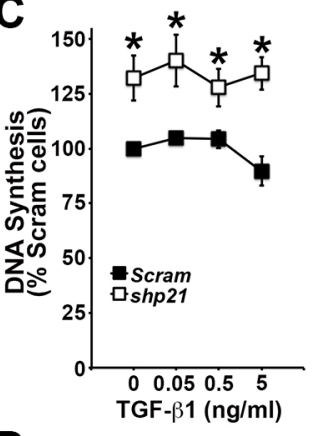

D

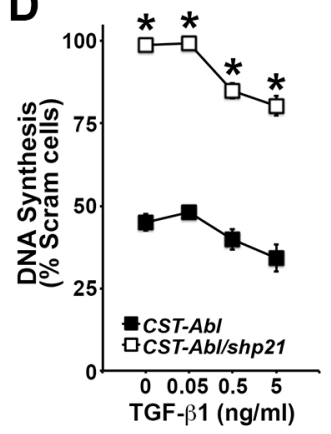

$\mathbf{E}$

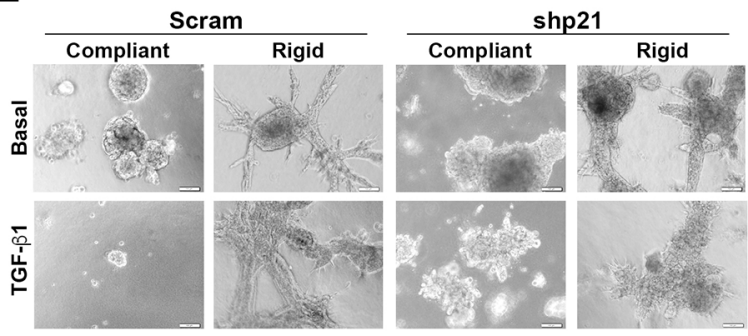

$\mathbf{F}$

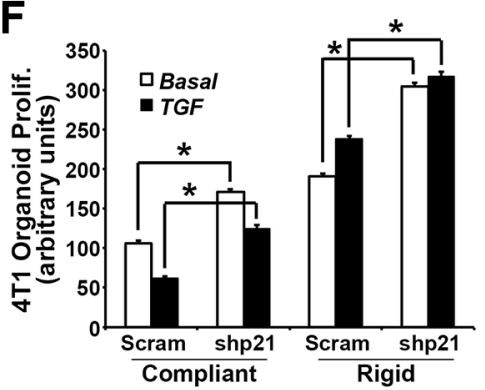

G
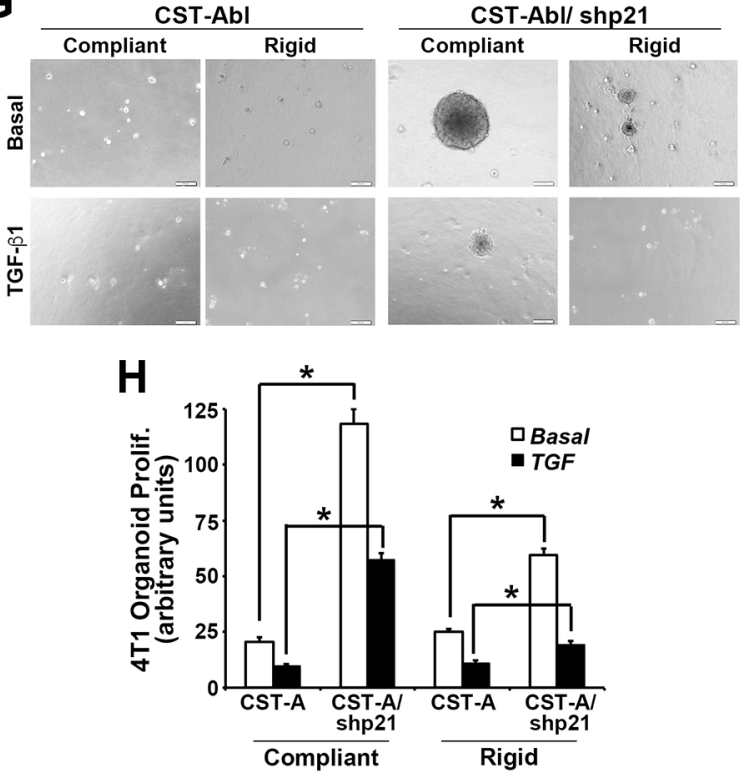

Figure 3: p21 expression is required for morphological normalization and cytostasis driven by CST-Abl. (A and B) Endogenous and genetically manipulated expression of 21 (i.e., shp21) in NMuMG, 4T1, and CST-Abl-expressing 4T1 cells was monitored by semi-quantitative real-time PCR (A), and by immunoblotting (B). Data are the mean $( \pm \mathrm{SE})$ of 3 independent experiments. ${ }^{*} P<0.05$. $(\mathbf{C}$ and $\mathbf{D})$ Alterations in DNA synthesis regulated by TGF- $\beta 1(0 \rightarrow 5 \mathrm{ng} / \mathrm{ml})$ was determined by $\left[{ }^{3} \mathrm{H}\right]$ thymidine incorporation assays. Data are the mean $( \pm \mathrm{SE})$ of 3 independent experiments as indicated. (E and F) 4T1 derivatives employed in Panels $C$ and D were propagated in the absence or presence of TGF- $\beta 1(5 \mathrm{ng} / \mathrm{ml})$ for 7 days in either compliant or rigid 3D-cultures as indicated. Alterations in organoid growth regulated by TGF- $\beta 1(0 \rightarrow 5 \mathrm{ng} / \mathrm{ml})$ was determined by Image $\mathrm{J}$ analyses. Data are the mean $( \pm \mathrm{SE})$ of 4 independent experiments as indicated. 


\section{p21-deficiency partially restores the}

\section{tumorigenicity of CST-Abl-expressing 4T1 cells}

Based on the ability of p21-deficiency to (i) enhance normal and malignant MEC proliferation and survival in 2D- and 3D-culture systems, and (ii) partially circumvent the anticancer activities of CST-Abl in 4T1 organoids (Figure 3), we next sought to determine whether p21deficiency could restore the tumorigenicity of CST-Ablexpressing 4T1 cells following their engraftment onto the mammary fat pads of syngeneic Balb/C mice. Figure 5 shows that rendering CST-Abl-expressing 4T1 cells deficient in p21 expression failed to restore overt signs of disease to these mice as gauged by regular palpation and caliper measurements, even out to 59 days post-inoculation when the mice were sacrificed and their mammary glands were recovered for pathological analyses (Figure 5A, 5B). Interestingly, we identified small fluctuant masses in the glands of 3 of 5 mice injected with p21-deficient CSTAbl-expressing 4T1 cells (Figure 5C), while no such abnormalities were observed in animals inoculated with their p21-expressing counterparts (data not shown). Histopathological analysis identified one mass as being a benign cutaneous cyst of epithelial origin associated with
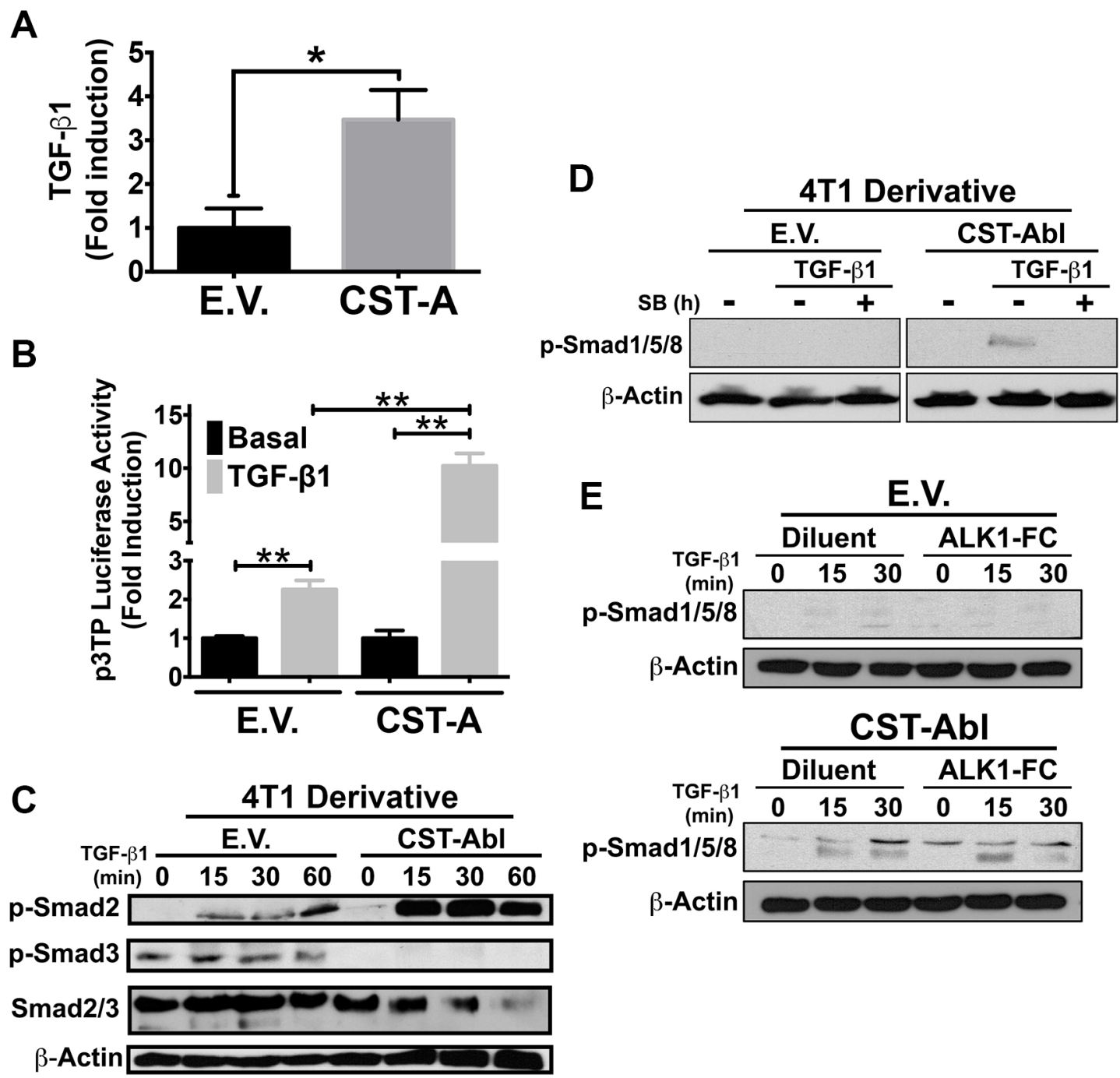

Figure 4: CST-Abl governs the coupling of TGF- $\beta$ to the activation of Smad2/3 and Smad1/5/8 in 4 T1 cells. (A) CST$\mathrm{Abl}$ expression induces the production and secretion of TGF- $\beta 1$ from $4 \mathrm{~T} 1$ cells as measured by ELISA assays. Data are the mean $( \pm \mathrm{SE})$ fold-induction of TGF- $\beta 1$ in 3 independent experiments. ${ }^{*} P<0.05$. (B) Parental (E.V.) and CST-A $\beta 1$ (CST-A)-expressing 4 T1 cells were transiently transfected with $\mathrm{p} 3 \mathrm{TP}-\mathrm{luciferase}$ and with $\mathrm{pCMV}-\beta$-gal, and subsequently were stimulated with TGF- $\beta 1(5 \mathrm{ng} / \mathrm{ml})$. Data are the mean $( \pm \mathrm{SE})$ fold-induction of luciferase activity normalized to that of $\beta$-gal in 3 independent experiments. $* * P<0.01$. (C) Parental

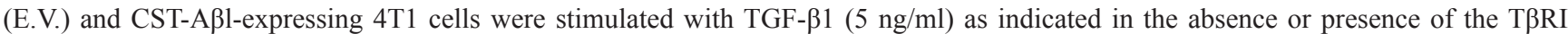
inhibitor, SB431542 (10 $\mu$ M; Panel D) or the BMP antagonist, ALK1-Fc (200 ng/ml; Panel E). Afterward, the activation status of Smad2, Smad3, and Smad1/5/8 were monitored by immunoblotting as indicated. Differences in protein loading were monitored by reprobing stripped membranes with antibodies against total Smad $2 / 3$ and $\beta$-actin as indicated. Data are representative images of 4 (C), 2 (D), or 2 (E) independent experiments, respectively. 
ductal dilation, while the second mass was determined to be a benign papillary epithelial tumor associated with squamous and columnar cell differentiation (Figure 5C). Thus, while depleting p21 expression in CST-Ablexpressing 4T1 cells results in the formation of benign cystic mammary lesions, this event nevertheless remained insufficient to fully circumvent the anticancer activities of activated c-Abl. Collectively, these findings suggest that elevated p21 expression is likely one component of a large scale reprogramming effort elicited by CST-Ablexpression in late-stage TNBC cells.

\section{CST-Abl expression abrogates 4T1 tumorigenicity by inducing a p21-dependent senescence}

Following their expression of CST-Abl, 4T1 cells form extremely small and perfectly spherical organoids when propagated in compliant 3D-cultures (Figure 3G; [27]). Indeed, organoids formed by CST-Abl-expressing $4 \mathrm{~T} 1$ cells appeared to be stable and could remain in this state for extended culture periods (e.g., > 1 month; data not shown), which in many respects recapitulated their inability to form tumors in mice despite their protracted residence within the mammary gland (Figure 2). The expression of p21 has been linked to senescence phenotypes [46-48], and as such, we speculated that one mechanism whereby CST-Abl suppresses TNBC tumorigenicity is through a p21-dependent senescent reaction. To test this supposition, we propagated control (i.e., scrambled shRNA) or p21-deficient CST-Abl- expressing 4T1 cells in compliant 3D-cultures over a span of 14 days, at which point the resulting organoids were stained for $\beta$-galactosidase-mediated cleavage of $\mathrm{X}$-gal (5-bromo-3-indolyl- $\beta$-D-galactorpyranoside) to monitor the extent of cellular senescence. Figure 6 shows that control CST-Abl-expressing 4T1 organoids failed to grow significantly beyond day 4 and remained perfectly spherical throughout the 14-day time-course. X-gal staining of fixed organoids indicated that control CSTAbl-expressing 4T1 cells expressed robust quantities of senescence-associated $\beta$-galactocidase by day 8 , demonstrating that these TNBCs underwent senescence between 4-8 days in compliant 3D-cultures (Figure 6). In stark contrast, organoids formed by p21-deficient CST-Abl-expressing 4T1 cells were significantly larger and displayed more heterogeneous morphologies, as well as exhibited delayed acquisition of senescent phenotypes as compared to their p21-expressing counterparts (Figure 6). Moreover, the rate at which CST-Ablexpressing 4T1 derivatives underwent senescence was unaffected by alterations in microenvironmental compliance (i.e., collagen supplementation; data not shown), nor was the expression of senescence-associated $\beta$-galactosidase activity ever detected in parental 4T1 cells cultured under identical conditions (data not shown). Collectively, these findings indicate that p21deficiency can delay, but not prevent, the ability of CST$\mathrm{Abl}$ to induce senescence in late-stage TNBCs, results that are consistent with the development of benign cystic lesions by p21-deficient CST-Abl-expressing 4T1 cells in mice (Figure 5C).
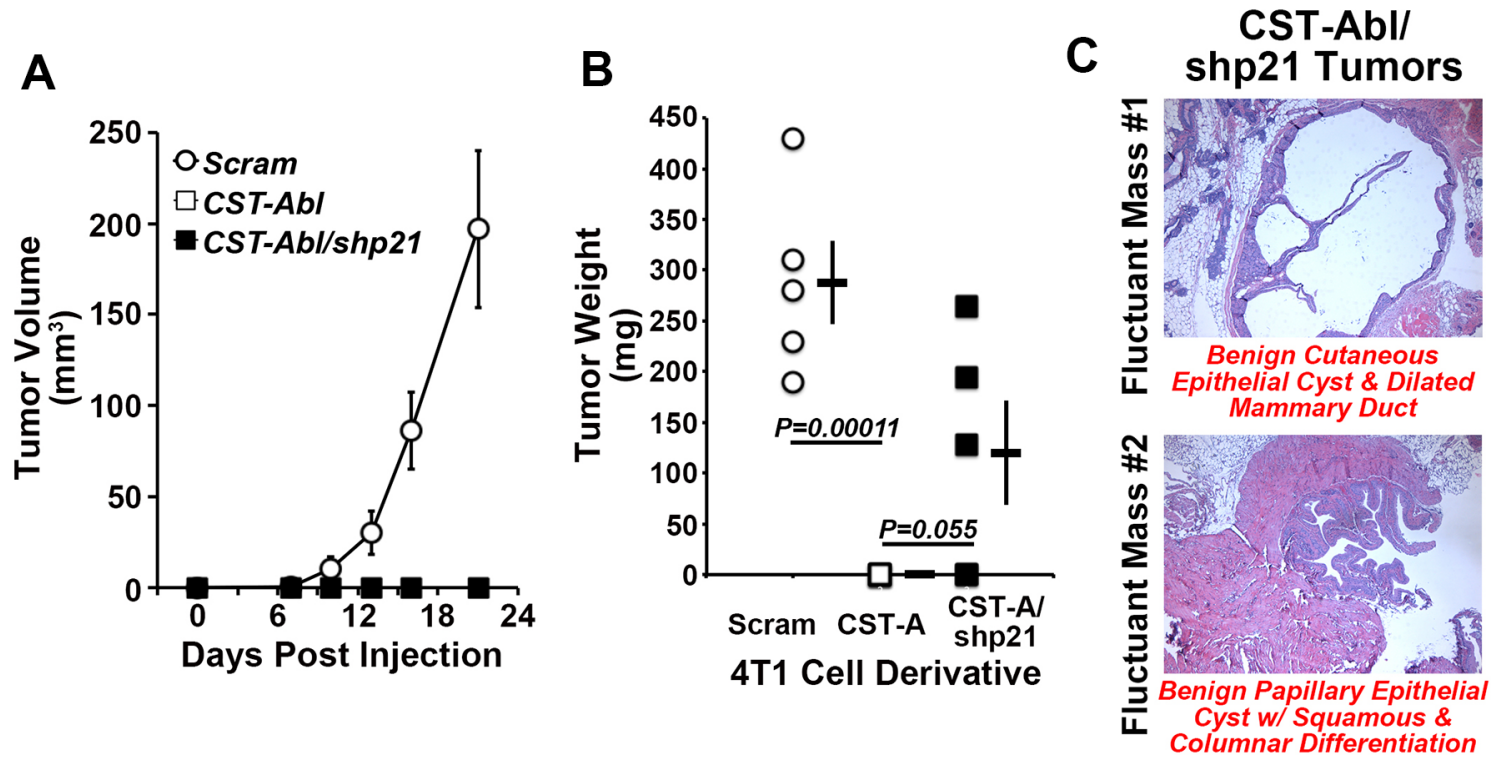

Figure 5: p21-deficiency partially restores the tumorigenicity of CST-Abl-expressing 4T1 cells. (A and B) Parental (i.e., Scram), CST-Abl-, and CST-Abl/shp21-expressing 4T1 cells were engrafted onto the mammary fat pads of Balb/C mice. The resultant tumor growth was measured by digital calipers (A), and by excising and weighing the tumors at the time of necropsy (B). Data are the mean $( \pm \mathrm{SE})$ tumor volumes $(\mathrm{A})$ and weights $(\mathrm{B})$. (C) H\&E staining of paraffin-embedded slices of mammary glands harvested from p21deficient CST-Abl-expressing 4T1 tumors. 


\section{c-Abl induces p21 expression via a TGF- $\beta 1-d e p e n d e n t$ reactivation of p53 expression in 4T1 cells}

The aforementioned findings led us to speculate the existence of an anticancer signaling axis comprised of $\mathrm{c}-\mathrm{Abl}$ and p21 in TNBCs. Indeed, c-Abl is well known for its ability to regulate apoptosis and cell cycle progression by modulating the activity of p53 family members in response to DNA damage [12,49] either through a direct induction of target gene expression (e.g., p73), or indirectly through c-Abl-mediated phosphorylation of MDM2, which releases p53 and facilitates its activation of target gene expression [50-52]. As expected, treating NMuMG cells with the DNA damage-inducing agent, 6-thioguanine (6-TG) resulted in massive cell death (Figure 7A), an event that contrasted sharply with the complete insensitivity of $4 \mathrm{~T} 1$ cells to undergo apoptosis in response to 6-TG (Figure 7A). Interestingly, enforced CST-Abl expression sensitized 4T1 cells to DNA damageinduced cell death elicited by 6-TG, suggesting that c-Abl expression enhances the anticancer activities of DNA damaging agents in TNBCs. Treatment with Nutlin-3, which inhibits the interaction between MDM2 and p53 or $\mathrm{p} 73$, had no effect on the sensitivity and survival of 4T1 cells to 6-TG (data not shown). Mechanistically, parental 4T1 cells were observed to be devoid of p53 expression, while their CST-Abl-expressing counterparts were found to harbor robust quantities of $\mathrm{p} 53 \mathrm{mRNA}$ and protein (Figure 7B). In light of the ability of p53 to induce p21 expression, we reasoned that CST-Abl might couple to $\mathrm{p} 21$ expression indirectly via activation of $\mathrm{p} 53$ expression. To test this hypothesis, we transiently transfected CST-Ablexpressing 4T1 cells with control (i.e., nontargeting) or p53-targeting siRNAs, of which the latter experimental condition dramatically downregulated $\mathrm{p} 21$ expression in CST-Abl-expressing 4T1 cells (Figure 7C). Moreover, treating CST-Abl-expressing 4T1 cells with the T $\beta R I$ inhibitor, SB431542 significantly reduced their expression of p53 (Figure 7D) and p21 (Figure 7E), suggesting that the reactivation of the $\mathrm{p} 53$ and $\mathrm{p} 21$ by c-Abl is dependent upon TGF- $\beta$ receptors. Taken together, these findings identify a novel c-Abl-dependent TGF- $\beta \rightarrow$ p $53 \rightarrow$ p 21 signaling axis that inhibits the tumorigenicity of TNBCs by inducing their acquisition of senescent phenotypes.

\section{c-Abl and p53 are discordantly expressed in triple negative breast cancer}

Lastly, we examined the expression patterns of c-Abl and p53 across normal and malignant breast tissues. In doing so, we observed a strong concordance for both tumor suppressors to be expressed in normal breast tissues obtained from mammoplastic reduction surgeries, and in luminal A and B breast cancer subtypes. In stark contrast, c-Abl and p53 exhibited highly discordant expression patterns in basal-like breast cancers (Figure 8A). c-Abl expression was also dramatically downregulated in a panel of TNBC PDX tumors as compared to normal human mammary epithelial cells (HMECs) isolated from mammoplastic reduction surgery (Figure 8B). Interestingly, TNBC PDX tumors exhibited a diverse range of p53 expression (Figure 8B) that was inversely related to the expression of c-Abl in identical PDX tissues (Figure 8C). Finally, we assessed the expression of c-Abl and p53 by immunostaining adjacent slices of a breast tissue microarray (TMA) that contained 157 breast tissues and spanned all major histological subtypes (Supplementary Figure S6A; [53]). These analyses determined that robust c-Abl expression trended to associate with improved overall patient survival (Supplementary Figure S6B); however, when we further discriminated for the expression status of $\mathrm{p} 53$, we found that wild-type $\mathrm{p} 53$ expression combined with robust expression of $\mathrm{c}-\mathrm{Abl}$ trended to provide better overall survival as compared to tumors that housed high expression of c-Abl and mutant p53 (Supplementary Figure $\mathrm{S} 6 \mathrm{C})$. Thus, the anticancer activities attributed to dual c-Abl and 553 expression appear to be more protective than those mediated by the singular stratification of c-Abl in human breast cancers. Collectively, these findings indicate that the levels of p53 expression and its mutational status are critical determinants of the tumor suppressing activities of c-Abl in human breast cancers.

\section{DISCUSSION}

Our previous findings [27] and those presented herein clearly show that the anticancer activities of CST$\mathrm{Abl}$ are robust, multifactorial, and dependent upon the expression and mutational status of $\mathrm{p} 53$. The essential genome guarding functions of $\mathrm{c}-\mathrm{Abl}$ in regulating DNA damage responses via $\mathrm{p} 53$ and $\mathrm{p} 73$ are well-established $[54,55]$; however, to our knowledge, our study is the first to establish the importance of an autocrine c-Abl $\rightarrow$ TGF$\beta \rightarrow \mathrm{T} \beta \mathrm{RI} \rightarrow \operatorname{Smad} 1 / 5 / 8: \operatorname{Smad} 2 \rightarrow \mathrm{p} 53 \rightarrow \mathrm{p} 21 \quad$ signaling axis in dictating MEC morphology and suppressing tumorigenesis. The importance of p53 in mediating the tumor suppressing activities of c-Abl cannot be overstated, as p53 is an essential tumor suppressor and guardian of the genome; it also serves in repressing the proliferation of mammary stem/progenitor cells [56]. Our findings indicate that c-Abl-mediated reactivation of $\mathrm{p} 53$ suppresses CSC renewal and expansion, which renders $4 \mathrm{~T} 1$ cells innocuous when engrafted into mice. Conversely, mutant p53 expression trended to reverse the overall survival benefit provided to breast cancer patients whose tumors retain high expression of c-Abl (Supplementary Figure S6), a finding that is highly significant in light of the fact that mutant p53 can promote oncogenic TGF- $\beta$ signaling [57]. Moreover, wild-type p53 and TGF- $\beta$ cooperate in stimulating the expression of their downstream effectors, particularly p 21 , whereas mutant p53 antagonizes these 
events in part by downregulating the expression of T $\beta$ RII [58]. Thus, it is tempting to speculate that mutant p53 underlies the initiation of oncogenic TGF- $\beta$-signaling and its ability to circumvent the tumor suppressing activities of c-Abl observed in our patient cohort. As such, the functional interaction between mutant p53 and c-Abl requires further evaluation related to their relevance in regulating breast cancer progression.

Although the mechanism whereby 4T1 cells lose p53 expression remains unknown, our findings indicate that oncogenic TGF- $\beta$ signaling plays an intimate role in this process. Indeed, we observed enforced c-Abl activity to drive p53 expression via TGF- $\beta$ stimulation of Smad1/5/8 and Smad2. Precisely how c-Abl rewires the TGF- $\beta$ pathway and its reactivation of $\mathrm{p} 53$ requires further investigation; however; c-Abl can phosphorylate Mdm2 at Tyr394, which stabilizes and activates p53 [51], as well as promotes its nuclear accumulation following DNA damage [59]. Accordingly, we observed 4T1 cells to elevate their expression of Mdm 2 and suppress that of $\mathrm{p} 53$ in response to TGF- $\beta$, events that were readily reversed in CST-Ablexpressing 4T1 cells (data not shown). Interestingly, when activated by genotoxic stress, ATM can stimulate Smad1 and promote its direct interaction with p53, thereby protecting p53 from Mdm2-mediated ubiquitination and degradation [60]. Thus, the loss of c-Abl expression in TNBCs may disinhibit Mdm2 activity, leading to the functional inactivation of p53 and the initiation of oncogenic signaling by TGF- $\beta$. Along these lines, we observed c-Abl and p53 to be readily co-expressed in normal human breast tissues, an event that rarely occurred in their malignant counterparts. The discordance in c-Abl and p53 expression patterns may explain the lack of efficacy provided by Imatinib to patients harboring cancers of the breast [19-21], thyroid [61], and prostate [62-64], all of which represent tissues that normally coexpress c-Abl and p53. Interestingly, the expression levels of c-Abl and p53 are inversely correlated in bone marrow, a tissue wherein c-Abl acquires oncogenic activity during the initiation of CML $[17,18]$. Thus, elucidating and ultimately inactivating the mechanisms operant in downregulating c-Abl expression and activity may provide a novel therapeutic strategy to restore p53 expression in distinct subtypes of breast cancer.

Lastly, our findings suggest the intriguing possibility that the anticancer activities of c-Abl occur predominantly in a cell-autonomous manner, and that $\mathrm{c}-\mathrm{Abl}$ dictates the coupling of TGF- $\beta$ receptors to various Smad family members. For instance, p21-deficiency dramatically increased the proliferative activity of NMuMG and 4T1 cells in both 2D- and 3D-cultures. Interestingly, TGF- $\beta$ induces extensive apoptosis in NMuMG cells cultured in

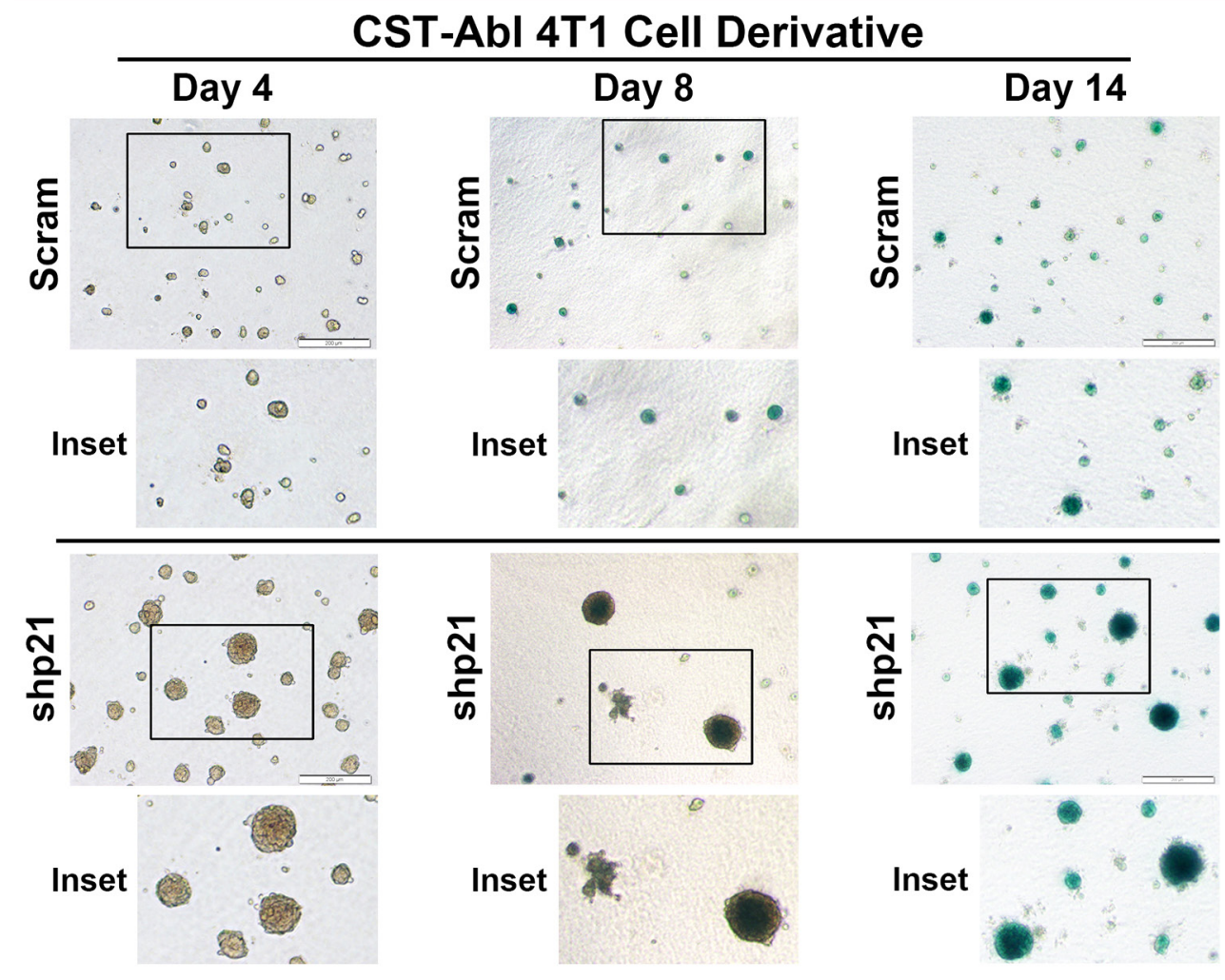

Figure 6: CST-Abl expression abrogates 4T1 tumorigenicity by inducing a p21-dependent senescence. CST-Abl-expressing 4T1 cells were transduced with scrambled (i.e., Scram) or p21 shRNA lentiviral particles. Afterward, the 4T1 derivatives were propagated in compliant 3D-cultures for 4-14 days, at which point they were fixed and stained for $\beta$-galactosidase expression. Photomicrographs are representative of 2 independent experiments. 
mechanically rigid microenvironments, an event that was noticeably absent in normal and malignant MECs rendered deficient in p21 expression. These findings reinforce the important links between mechanotransduction and TGF- $\beta$ signaling [27, 42, 65-68] and suggest that the uncoupling of c-Abl to p21 expression represents an early event in mammary tumorigenesis, perhaps serving to enhance the dedifferentiation, expansion, and self-renewal properties of breast CSCs. Indeed, when stimulated with TGF- $\beta$, CST-Abl-expressing 4T1 cells expressed robust levels of the MET-associated transcription factors, Sox 2 and KLF-4. Moreover, enforced expression of KLF-4 in 4T1 cells suppressed their tumorigenicity and metastasis, doing so by inhibiting Snail expression and its induction of EMT programs [69]. Likewise, KLF-4 induces p21 expression in a context-specific manner, such that inactivation of p21 converts KLF-4 from a tumor suppressor to a tumor promoter $[70,71]$. It is interesting to note that KLF-4 also interacts physically with Smad1 [72], a BMPregulated Smad whose unusual activation by TGF- $\beta$ we show is governed by CST-Abl. BMPs belong to the TGF- $\beta$ superfamily and have been shown to inhibit TGF$\beta$-dependent EMT and the self-renewal properties of CSCs; they also induce dormant states in disseminated breast cancer cells, thereby preventing their metastatic outgrowth [73-75]. Accumulating evidence also indicates that TGF- $\beta$ can engage and activate Smad1/5/8 during tumor progression [43-45]. Somewhat surprisingly, we
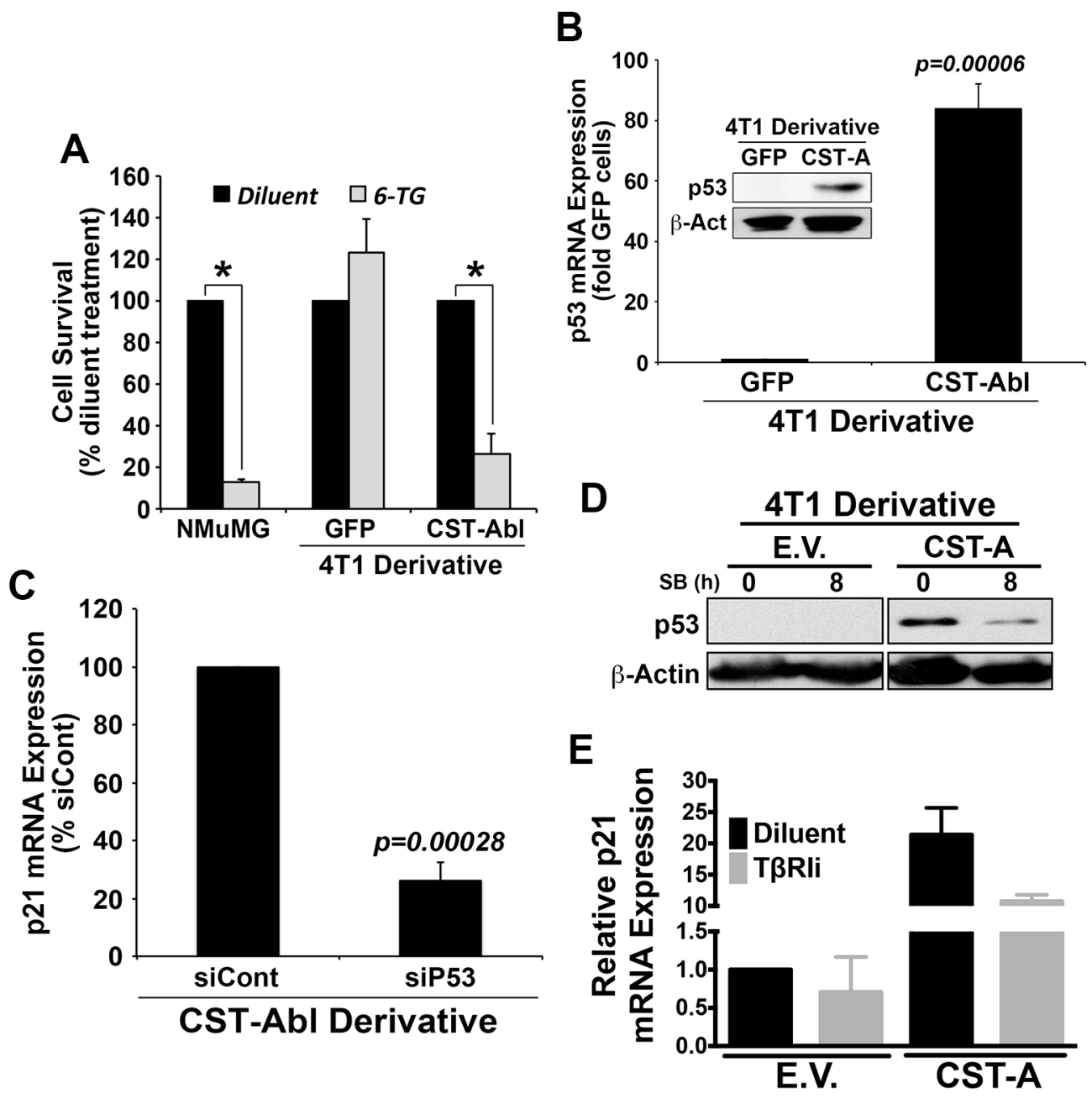

Figure 7: c-Abl induces p21 expression via a TGF- $\beta 1$ dependent reactivation of p53 expression in 4T1 cells. (A) NMuMG, parental 4T1 (i.e., GFP), and CST-Abl-expressing 4T1 cells were incubated with 6-thioguanine (6-TG) for $72 \mathrm{~h}$. Data are the mean ( \pm SE) percentage of surviving cells observed in 3 independent experiments. $* P<0.05$. (B) Expression of p53 mRNA and protein (inset) in parental (i.e., GFP) and CST-Abl-expressing 4T1 cells. Data are the mean ( \pm SE) of 3 independent experiments. (C) CST-Abl-expressing 4T1 cells were transiently transfected with nontargeting (i.e., siCont) or p53-targeting siRNA. Differences in $\mathrm{p} 21$ expression were determined on day 5 by semi-quantitative real-time PCR. Data are the mean $( \pm$ SE) of 3 independent experiments. (D) Parental (E.V.) and CST-Abl-expressing (CST-A) 4T1 cells were incubated for $8 \mathrm{~h}$ in the absence or presence of SB431542 $(10 \mu \mathrm{M})$ as indicated, at which point differences in p53 expression were determined by immunoblotting. Data are representative of 2 independent experiments. (E) Parental (E.V.) and CST-Ablexpressing (CST-A) 4T1 cells were grown in compliant 3D-cultures for $60 \mathrm{~h}$ in the absence or presence of SB431542 (10 $\mu \mathrm{M})$. Afterward, p21 mRNA expression was determined by semi-quantitative real-time PCR. Data are the mean $( \pm \mathrm{SD})$ of 2 independent experiments. 
found c-Abl to serve as a molecular switch that couples Smad1/5/8 signaling to that of Smad2, an event that transpires in the absence of Smad3 and its propensity to enhance tumorigenesis. Likewise, phosphorylated Smad3 can form a complex with Smads 1 and 5 to inhibit BMP-dependent signaling, thereby preventing the ability of TGF- $\beta$ to induce the expression of BMPresponsive genes [76]. Previous studies have also found that (i) c-Abl phosphorylates the type I BMP receptor (BMPR1A) to differentially regulate canonical and noncanonical BMP pathways to promote osteoblast differentiation [77], and (ii) BMP-2-induced c-Abl kinase activity is required for the osteoclast formation through coordinate phosphorylation of BMPR1A and Smad1/5/8 [78]. Thus, by preventing Smad3 activation by TGF- $\beta$, $\mathrm{c}-\mathrm{Abl}$ expression and activity favor the induction of MET

A
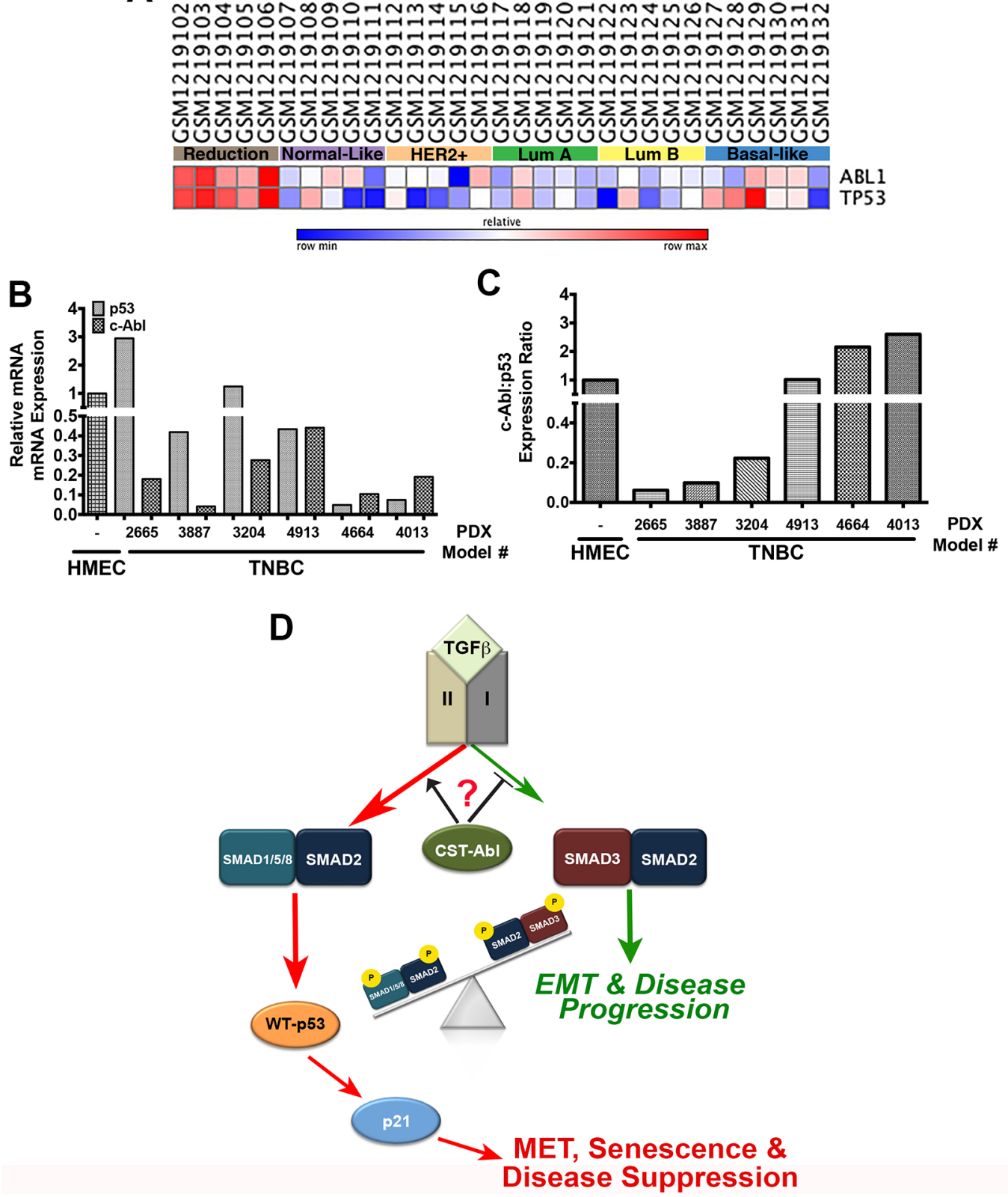

Figure 8: c-Abl and p53 are discordantly expressed in breast cancer. (A) c-Abl and p53 mRNA expression in the indicated NCBI geo datasets was analyzed by GENE-E (www.broadinstitute.org/cancer/software/GENE-E). (B) c-Abl and p53 mRNA expression was determined by semi-quantitative real-time PCR in normal HMEC organoids and TNBC PDX models. (C) The ratio of c-Abl:p53 expression determined in Panels $C$ and $D$ indicate that these tumor suppressors are discordantly expressed TNBC tumors. (D) Representative model highlighting the necessity of c-Abl expression and activity for the induction of MET reprogramming and TNBC tumor suppression, which transpires through an imbalance in activation of pSmad2:pSmad1/5/8 relative to that of $\mathrm{pSmad} 3$ in response to increased autocrine TGF- $\beta 1$ signaling. Questions remain as to the precise role activated c-Abl plays in driving the imbalances in Smad activation by TGF- $\beta$. 
and senescence programs via Smad1/5/8- and Smad2dependent transcriptional programs (Figure 8D.) Future studies need to assess whether the pro-BMP activities of $\mathrm{c}-\mathrm{Abl}$ transpire through alterations in either the production of BMP ligands (i.e., increased) or antagonists (i.e., decreased), as well as determine the extent which c-Abl orchestrates T $\beta R I$-mediated activation of Smad1/5/8 in TNBCs.

\section{MATERIALS AND METHODS}

\section{Cell lines and retroviral vectors}

Normal murine NMuMG mammary epithelial cells and metastatic murine 4T1 breast cancer cells were obtained from ATCC (Manassas, VA) and cultured as described previously [27]. A retroviral vector (pMSCVhygromycin) that encoded murine CST-Abl (type IV) was generously provided by Dr. Tony Hunter (Salk Institute, La Jolla, CA; [79-81] and used to produce polyclonal populations of 4T1 cell lines that stably expressed either empty vector (i.e., parental) or CST-Abl as previously described [27]. Murine p21 expression was functionally disrupted by transducing NMuMG and 4T1 derivatives with lentiviral particles that encoded for shRNA against p21 (cat\# RMM4534-NM_001111099, Open Biosystems, Huntsville, AL) as described previously [27]. The extent of p21-deficiency was determined by real-time PCR and immunoblotting as described below.

\section{TGF- $\beta 1$ Enzyme-linked immunosorbent assay (ELISA)}

The production and secretion of TGF- $\beta 1$ from 4T1 cell derivatives was measured using the mouse TGF- $\beta 1$ Quantikine ELISA kit (MB100B; R\&D Systems, Minneapolis, MN) according to the manufacturer's instructions. Briefly, 4T1 cell derivatives were cultured for $24 \mathrm{hr}$ in serum-free DMEM, at which point the conditioned-media was collected, centrifuged at $500 \mathrm{~g}$ for $3 \mathrm{~min}$, and acidified to measure total TGF- $\beta 1$ concentrations (i.e., latent and active). The protein content of the remaining adherent 4T1 derivatives was determined and used to normalize TGF- $\beta 1$ concentrations (i.e., TGF- $\beta 1 \mathrm{pg} / \mathrm{mg}$ protein).

\section{Mammary gland reconstitution, imaging, and immunohistochemistry}

Mammary gland reconstitution analyses were performed as previously described [82]. Briefly, 3 -week-old female Balb/C mice (6 mice/cell line) were anesthetized under isofluorane gas to permit the surgical removal of the left inguinal \#4 mammary gland and lymph node, except for a small dorsal segment of the fat pad that was reserved and injected with either parental (i.e., GFP-expressing) or CST-Abl-expressing 4T1 cells (300,000 cells/injection). At 8 -weeks post-surgery, the mice were sacrificed and the manipulated glands were removed and whole-mounted between slides to immediately image GFP expression on a Leica fluorescent microscope. The right inguinal \#4 mammary glands were also harvested at this time and served as positive controls for mammary gland development, while cleared mammary fat pads injected with PBS served as negative controls for mammary gland reconstitution. Following GFP imaging, the whole glands were formalin fixed and paraffin embedded (IHCTech, Aurora, CO) prior to assessing overall glandular morphology and development by hematoxylin and eosin (H\&E) staining, and by immunohistochemistry for GFP and $\beta$-galactosidase expression (IHCTech, Aurora, CO).

\section{Mammosphere assays}

Mammosphere assays were executed as described previously [83]. Briefly, single cell suspensions of NMuMG or 4T1 derivatives were prepared and plated $(10,000$ cells/well) in 6-well, ultra-low attachment plates (Corning, Corning, NY). The cultures were fed every 3-4 days with serum-free DMEM (Invitrogen, Carlsbad, CA) supplemented with bFGF (20 ng/ml; Invitrogen), EGF (20 ng/ml; Invitrogen), B27 (Life Technologies, Grand Island, NY), and heparin (4 mg/ml; Sigma, St. Louis, MO), and the resulting mammospheres were enumerated on day 7 by light microscopy. Afterward, the primary mammospheres were collected by gentle centrifugation, and subsequently were disrupted by trypsinization and serially passaged at a density of 1,000 cells/well for an additional 7 days to assess the formation of secondary mammospheres.

\section{Semi-quantitative real-time PCR}

4T1 (250,000 cells/well) or NMuMG (350,000 cells/ well) cells were cultured overnight in 6-well plates. The following morning, the cells were fed with fresh media and immediately incubated in the absence or presence of TGF- $\beta 1(5 \mathrm{ng} / \mathrm{ml})$ for $48 \mathrm{hr}$ at $37^{\circ} \mathrm{C}$. Afterward, total RNA was harvested and employed to monitor the expression of Sox-2, Klf-4, and $p 21$ by semi-quantitative real-time PCR as described [27]. Total RNA was also harvested from frozen sections of low-passage human breast PDX tumors [84] and used to monitor the expression of $c-A b l$ and $p 53$ by semi-quantitative real-time PCR. In all cases, differences in RNA concentration for individual genes were normalized to their corresponding RNA signals for GAPDH. The oligonucleotides primer pairs used are provided in Supplementary Table S2.

\section{Cell biological assays and immunoblotting}

The ability of TGF- $\beta 1(0 \rightarrow 5 \mathrm{ng} / \mathrm{ml})$ to impact DNA synthesis in NMuMG and 4T1 derivatives was determined 
by measuring the incorporation of $\left[{ }^{3} \mathrm{H}\right]$ thymidine into cellular DNA as described [85]. The coupling of TGF- $\beta$ to p3TP- and BRE-luciferase reporter gene expression was undertaken as described previously [42]. Likewise, the ability of TGF- $\beta 1$ or c-Abl to impact either the expression or activity of various intracellular effector molecules was determined by immunoblotting as described [42]. Antibodies used herein were as follows: (a) anti-p21 (1:500; Santa Cruz Biotechnology, Santa Cruz, CA); (b) anti-p53 (1:500; EDM Millipore, Billerica, MA); (c) antic-Abl (1:500; BD Biosciences, San Jose, CA); (d) antiMMP-9 (1:500; Sigma); (e) anti-phospho-Smad1/5/8 (1:500; Cell Signaling Technologies); (f) anti-phosphoSmad2 (1:1000; Cell Signaling Technologies); $(g)$ antiphospho-Smad3 (1:1000:Cell Signaling Technologies); (h) anti-Smad2/3 (1:1000;Cell Signaling Technologies); and (i) anti- $\beta$-actin (1:1000; Sigma-Aldrich).

\section{3-dimensional (3D) culture and $\beta$-galactosidase staining}

NMuMG or 4T1 derivatives (7,500 cells/well) were cultured onto Cultrex cushions $(150 \mathrm{ml}$; Trevigen, Gaithersburg, MD) housed in 48-well plates that contained complete media supplemented with 5\% Cultrex. Where indicated, the Cultrex cushions were rendered biomechanically rigid by the inclusion of type I collagen (3 mg/ml; BD Biosciences), and cells propagated under compliant or rigid $3 \mathrm{D}$-culture conditions were incubated in the absence or presence of TGF- $\beta 1(5 \mathrm{ng} / \mathrm{ml})$ as indicated. Differences in organoid growth were monitored by brightfield microscopy and quantified using Image J64 (version $1.46)$, while variations in $\beta$-galactosidase expression were detected and visualized using the Beta-Galactosidase Staining Kit (Mirus Bio LLC, Madison, WI) according to the manufacturer's instructions. Additionally, 4T1 derivatives $(400,000$ cells/well) were also cultured for 60 hr on Cultrex cushions $(400 \mu \mathrm{l})$ housed in 6-well plates in the absence or presence of the T $\beta$ RI inhibitor, SB431542 $(10 \mu \mathrm{M})$ as indicated. Afterward, the resulting organoids were using the Cultrex 3D-culture cell harvesting kit (3448-020-K; Trevigen) according to the manufacturer's recommendations, at which point total RNA was isolated and purified as described above.

\section{Tumor studies}

4T1 cells engineered to express empty vector (i.e., Scram), CST-Abl, or CST-Abl in combination with shRNA against p21 (i.e., CST-Abl/sh21) were engrafted into the 4th inguinal mammary fat pad $(10,000$ cells/ injection) of syngeneic 6-8 week old female Balb/C mice (Jackson Laboratories). Primary 4T1 tumor growth was monitored as described [27]. Upon completion of the studies, the injected mammary fat pads and primary $4 \mathrm{~T} 1$ tumors were excised and weighed between days 21-28, and again on day 59 post-inoculation. All animal studies were performed according to animal protocol procedures approved by the Institutional Animal Care and Use Committee of the University of Colorado.

\section{DNA damage and survival assays}

Parental (i.e., GFP) NMuMG cells, as well as parental (i.e., GFP) or CST-Abl-expressing 4T1 cells were cultured and allowed to adhere overnight in 48-well plates (20,000 cells/well), at which point they were exposed to 6-thioguanine ( $60 \mu \mathrm{M}$; Sigma-Aldrich) for $72 \mathrm{~h}$ at $37^{\circ} \mathrm{C}$. Afterward, the surviving cells were (i) washed twice in ice-cold in PBS; (ii) immediately fixed in 95\% ethanol for $60 \mathrm{~min}$ at room temperature; (iii) stained with crystal violet (BD Biosciences) for $30 \mathrm{~min}$; and (iv) destained with deionized $\mathrm{H}_{2} \mathrm{O}$. Afterward, the extent of cell survival relative to diluent treated cells was quantified by imaging densitometry of stained tissue culture wells using the Image J (version 1.46).

\section{RNA interference studies}

CST-Abl-expressing 4T1 cells lacking expression of p53 were generated using SMARTpool siRNAs (50 nM) according to the manufacturer's recommendations (Dharmacon, Lafayette, CO) and as previously described [86]\}. Ninety-six hr post-transfection, the cells were harvested and total RNA was isolated to monitor the expression of p21 mRNA by semi-quantitative realtime PCR as described above. CST-Abl cell transfection efficiency was monitored by co-transfection with siGLO RISC-Free siRNA (Dharmacon), which was visualized using fluorescent microscopy.

\section{Statistical analyses}

Statistical values were defined using an unpaired Student's $t$-test with a $P$ value of $<0.05$ considered significant.

\section{Abbreviations}

3D, 3-dimensional; CML, chronic myelogenous leukemia; CST, constitutively-active; E-cad, epithelial cadherin; EMT, epithelial mesenchymal transition; MEC, mammary epithelial cell; MET, mesenchymal-epithelial transition; MMP, matrix metalloproteinase; TGF- $\beta$, transforming growth factor- $\beta$; TNBC, triple-negative breast cancer.

\section{ACKNOWLEDGMENTS}

Members of the Schiemann Laboratory are thanked for critical reading of the manuscript. We also thank Dr. Paul Jedlicka (University of Colorado-Denver, Aurora, CO) 
for providing pathology expertise and support, as well as acknowledge the expert assistance provided by Drs. Erica McCoy and Ritsuko Iwanaga (University of ColoradoDenver, Aurora, CO) in undertaking the mammary gland reconstitution and mammosphere analyses, respectively. Finally, we acknowledge the expertise provided by members of the Case Comprehensive Cancer Center's Tissue Resources Core, as well as thanks Dr. Mark Jackson for providing RNA from human mammary epithelial cells isolated from reduction mammoplasties.

\section{GRANT SUPPORT}

Research support was provided in part by the National Institutes of Health to W.P.S. (CA129359, CA177069, and CA194518) and C.D.M (CA180670), and by the Department of Defense CDMRP Predoctoral Fellowship to T.M.A. (BC083323).

\section{CONFLICTS OF INTEREST}

The Authors do not have any conflicts of interest.

\section{REFERENCES}

1. Jallal H, Valentino ML, Chen G, Boschelli F, Ali S, Rabbani SA. A Src/Abl kinase inhibitor, SKI-606, blocks breast cancer invasion, growth, and metastasis in vitro and in vivo. Cancer Res. 2007; 67:1580-8.

2. Kain KH, Gooch S, Klemke RL. Cytoplasmic c-Abl provides a molecular 'Rheostat' controlling carcinoma cell survival and invasion. Oncogene. 2003; 22:6071-80.

3. Lin J, Arlinghaus R. Activated c-Abl tyrosine kinase in malignant solid tumors. Oncogene. 2008; 27:4385-91.

4. Srinivasan D, Plattner R. Activation of Abl tyrosine kinases promotes invasion of aggressive breast cancer cells. Cancer Res. 2006; 66:5648-55.

5. Srinivasan D, Sims JT, Plattner R. Aggressive breast cancer cells are dependent on activated Abl kinases for proliferation, anchorage-independent growth and survival. Oncogene. 2008; 27:1095-105.

6. Suzuki J, Shishido T. Regulation of cellular transformation by oncogenic and normal Abl kinases. J Biochem. 2007; 141:453-8.

7. He X, Zheng Z, Song T, Wei C, Ma H, Ma Q, Zhang Y, $\mathrm{Xu}$ Y, Shi W, Ye Q, Zhong H. c-Abl regulates estrogen receptor $\alpha$ transcription activity through its stabilization by phosphorylation. Oncogene. 2010; 29:2238-51.

8. Zhao H, Ou-Yang F, Chen IF, Hou MF, Yuan SS, Chang HL, Lee YC, Plattner R, Waltz SE, Ho SM, Sims J, Wang SC. Enhanced resistance to tamoxifen by the c-ABL protooncogene in breast cancer. Neoplasia. 2010; 12:214-23.

9. Sirvent A, Boureux A, Simon V, Leroy C, Roche S. The tyrosine kinase $\mathrm{Abl}$ is required for Src-transforming activity in mouse fibroblasts and human breast cancer cells. Oncogene. 2007; 26:7313-23.

10. Shaul Y. c-Abl: activation and nuclear targets. Cell Death Differ. 2000; 7:10-6.

11. Truong T, Sun G, Doorly M, Wang JY, Schwartz MA. Modulation of DNA damage-induced apoptosis by cell adhesion is independently mediated by p53 and c-Abl. Proc Natl Acad Sci USA. 2003; 100:10281-6.

12. Wagner MW, Li LS, Morales JC, Galindo CL, Garner HR, Bornmann WG, Boothman DA. Role of c-Abl kinase in DNA mismatch repair-dependent G2 cell cycle checkpoint arrest responses. J Biol Chem. 2008; 283:21382-93.

13. Yuan ZM, Shioya H, Ishiko T, Sun X, Gu J, Huang YY, Lu H, Kharbanda S, Weichselbaum R, Kufe D. p73 is regulated by tyrosine kinase $\mathrm{c}-\mathrm{Abl}$ in the apoptotic response to DNA damage. Nature. 1999; 399:814-7.

14. Noren NK, Foos G, Hauser CA, Pasquale EB. The EphB4 receptor suppresses breast cancer cell tumorigenicity through an Abl-Crk pathway. Nat Cell Biol. 2006; 8:815-25.

15. Wang JY. Eph tumour suppression: the dark side of Gleevec. Nat Cell Biol. 2006; 8:785-6.

16. Rappa G, Anzanello F, Lorico A. Imatinib mesylate enhances the malignant behavior of human breast carcinoma cells. Cancer Chemother Pharmacol. 2011; 67:919-26.

17. Druker BJ. Circumventing resistance to kinase-inhibitor therapy. N Engl J Med. 2006; 354:2594-6.

18. Soverini S, Martinelli G, Iacobucci I, Baccarani M. Imatinib mesylate for the treatment of chronic myeloid leukemia. Expert Rev Anticancer Ther. 2008; 8:853-64.

19. Chew HK, Barlow WE, Albain K, Lew D, Gown A, Hayes DF, Gralow J, Hortobagyi GN, Livingston R. A phase II study of imatinib mesylate and capecitabine in metastatic breast cancer: Southwest Oncology Group Study 0338. Clin Breast Cancer. 2008; 8:511-5.

20. Cristofanilli M, Morandi P, Krishnamurthy S, Reuben JM, Lee BN, Francis D, Booser DJ, Green MC, Arun BK, Pusztai L, Lopez A, Islam R, Valero V, et al. Imatinib mesylate (Gleevec) in advanced breast cancer-expressing C-Kit or PDGFR- $\beta$ : clinical activity and biological correlations. Ann Oncol. 2008; 19:1713-9.

21. Modi S, Seidman AD, Dickler M, Moasser M, D'Andrea G, Moynahan ME, Menell J, Panageas KS, Tan LK, Norton L, Hudis CA. A phase II trial of imatinib mesylate monotherapy in patients with metastatic breast cancer. Breast Cancer Res Treat. 2005; 90:157-63.

22. Taylor MA, Parvani JG, Schiemann WP. The pathophysiology of epithelial-mesenchymal transition induced by transforming growth factor- $\beta$ in normal and malignant mammary epithelial cells. J Mammary Gland Biol Neoplasia. 2010; 15:169-90.

23. Parvani JG, Taylor MA, Schiemann WP. Noncanonical TGF- $\beta$ signaling during mammary tumorigenesis. J Mammary Gland Biol Neoplasia. 2011; 16:127-46. 
24. Lee YH, Schiemann WP. Chemotherapeutic targeting of the transforming growth factor- $\beta$ pathway in breast cancers. Breast Cancer Manag. 2014; 3:73-85.

25. Foulkes WD, Smith IE, Reis-Filho JS. Triple-negative breast cancer. N Engl J Med. 2010; 363:1938-48.

26. Carey L, Winer E, Viale G, Cameron D, Gianni L. Triple-negative breast cancer: disease entity or title of convenience? Nat Rev Clin Oncol. 2010; 7:683-92.

27. Allington TM, Galliher-Beckley AJ, Schiemann WP. Activated Abl kinase inhibits oncogenic transforming growth factor- $\beta$ signaling and tumorigenesis in mammary tumors. FASEB J. 2009; 23:4231-43.

28. Finak G, Bertos N, Pepin F, Sadekova S, Souleimanova M, Zhao H, Chen H, Omeroglu G, Meterissian S, Omeroglu A, Hallett M, Park M. Stromal gene expression predicts clinical outcome in breast cancer. Nat Med. 2008; 14:518-27.

29. Richardson AL, Wang ZC, De Nicolo A, Lu X, Brown M, Miron A, Liao X, Iglehart JD, Livingston DM, Ganesan S. $\mathrm{X}$ chromosomal abnormalities in basal-like human breast cancer. Cancer Cell. 2006; 9:121-32.

30. Loh YH, Yang L, Yang JC, Li H, Collins JJ, Daley GQ. Genomic approaches to deconstruct pluripotency. Annu Rev Genomics Hum Genet. 2011; 12:165-85.

31. Li R, Liang J, Ni S, Zhou T, Qing X, Li H, He W, Chen J, Li F, Zhuang Q, Qin B, Xu J, Li W, et al. A mesenchymalto-epithelial transition initiates and is required for the nuclear reprogramming of mouse fibroblasts. Cell Stem Cell. 2010; 7:51-63.

32. Allington TM, Schiemann WP. The Cain and Abl of epithelial-mesenchymal transition and transforming growth factor- $\beta$ in mammary epithelial cells. Cells Tissues Organs. 2011; 193:98-113.

33. Wendt MK, Allington TM, Schiemann WP. Mechanisms of the epithelial-mesenchymal transition by TGF- $\beta$. Future Oncol. 2009; 5:1145-68.

34. Egeblad M, Littlepage LE, Werb Z. The fibroblastic coconspirator in cancer progression. Cold Spring Harb Symp Quant Biol. 2005; 70:383-8.

35. Yan C, Boyd DD. Regulation of matrix metalloproteinase gene expression. J Cell Pysiol. 2007; 211:19-26.

36. Lee YH, Albig AR, Regner M, Schiemann BJ, Schiemann WP. Fibulin-5 initiates epithelial-mesenchymal transition (EMT) and enhances EMT induced by TGF- $\beta$ in mammary epithelial cells via a MMP-dependent mechanism. Carcinogenesis. 2008; 29:2243-51.

37. Fisher KE, Fei Q, Laird ER, Stock JL, Allen MR, Sahagan BG, Strick CA. Engineering autoactivating forms of matrix metalloproteinase- 9 and expression of the active enzyme in cultured cells and transgenic mouse brain. Biochemistry. 2002; 41:8289-97.

38. Abbas T, Dutta A. p21 in cancer: intricate networks and multiple activities. Nature Rev Cancer. 2009; 9:400-14.

39. Abukhdeir AM, Park BH. P21 and p27: roles in carcinogenesis and drug resistance. Expert Rev Mol Med. 2008; 10:e19.
40. Moustakas A, Pardali K, Gaal A, Heldin CH. Mechanisms of TGF- $\beta$ signaling in regulation of cell growth and differentiation. Immunol Lett. 2002; 82:85-91.

41. Caldon CE, Sutherland RL, Musgrove E. Cell cycle proteins in epithelial cell differentiation: implications for breast cancer. Cell cycle. 2010; 9:1918-28.

42. Taylor MA, Amin J, Kirschmann DA, Schiemann WP. Lysyl oxidase contributes to mechanotransduction-mediated regulation of transforming growth factor- $\beta$ signaling in breast cancer cells. Neoplasia. 2011; 13:406-18.

43. Holtzhausen A, Golzio C, How T, Lee YH, Schiemann WP, Katsanis N, Blobe GC. Novel bone morphogenetic protein signaling through Smad2 and Smad3 to regulate cancer progression and development. FASEB J. 2014; 28:1248-67.

44. Liu IM, Schilling SH, Knouse KA, Choy L, Derynck R, Wang XF. TGF $\beta$-stimulated Smad1/5 phosphorylation requires the ALK5 L45 loop and mediates the pro-migratory TGFbeta switch. EMBO J. 2009; 28:88-98.

45. Wrighton $\mathrm{KH}$, Lin X, Yu PB, Feng XH. Transforming growth factor $\beta$ can stimulate Smad1 phosphorylation independently of bone morphogenic protein receptors. J Biol Chem. 2009; 284:9755-63.

46. Kang JY, Kim JJ, Jang SY, Bae YS. The p53-p21 (Cip1/ WAF1) pathway is necessary for cellular senescence induced by the inhibition of protein kinase CKII in human colon cancer cells. Mol Cells. 2009; 28:489-94.

47. Romanov VS, Abramova MV, Svetlikova SB, Bykova TV, Zubova SG, Aksenov ND, Fornace AJ, Jr., Pospelova TV, Pospelov VA. p21 (Waf1) is required for cellular senescence but not for cell cycle arrest induced by the HDAC inhibitor sodium butyrate. Cell Cycle. 2010; 9:3945-55.

48. Shen H, Maki CG. Persistent p21 expression after Nutlin3 a removal is associated with senescence-like arrest in $4 \mathrm{~N}$ cells. J Biol Chem. 2010; 285:23105-14.

49. Li LS, Morales JC, Hwang A, Wagner MW, Boothman DA. DNA mismatch repair-dependent activation of c-Abl/ p73alpha/GADD45 $\alpha$-mediated apoptosis. J Biol Chem. 2008; 283:21394-403.

50. Waning DL, Lehman JA, Batuello CN, Mayo LD. c-Abl phosphorylation of $\mathrm{Mdm} 2$ facilitates Mdm2-Mdmx complex formation. J Biol Chem. 2011; 286:216-22.

51. Goldberg Z, Vogt Sionov R, Berger M, Zwang Y, Perets R, Van Etten RA, Oren M, Taya Y, Haupt Y. Tyrosine phosphorylation of Mdm2 by c-Abl: implications for $\mathrm{p} 53$ regulation. EMBO J. 2002; 21:3715-27.

52. Sionov RV, Moallem E, Berger M, Kazaz A, Gerlitz O, BenNeriah Y, Oren M, Haupt Y. c-Abl neutralizes the inhibitory effect of Mdm2 on p53. J Biol Chem. 1999; 274:8371-4.

53. Sizemore ST, Sizemore GM, Booth CN, Thompson CL, Silverman P, Bebek G, Abdul-Karim FW, Avril S, Keri RA. Hypomethylation of the MMP7 promoter and increased expression of MMP7 distinguishes the basal-like breast cancer subtype from other triple-negative tumors. Breast Cancer Res Treat. 2014; 146:25-40. 
54. Levav-Cohen Y, Goldberg Z, Zuckerman V, Grossman T, Haupt S, Haupt Y. C-Abl as a modulator of p53. Biochem Biophys Res Commun. 2005; 331:737-49.

55. Greuber EK, Smith-Pearson P, Wang J, Pendergast AM. Role of ABL family kinases in cancer: from leukaemia to solid tumours. Nat Rev Cancer. 2013; 13:559-71.

56. Tao L, Roberts AL, Dunphy KA, Bigelow C, Yan H, Jerry DJ. Repression of mammary stem/progenitor cells by p53 is mediated by Notch and separable from apoptotic activity. Stem Cells. 2010; 29:119-27.

57. Adorno M, Cordenonsi M, Montagner M, Dupont S, Wong C, Hann B, Solari A, Bobisse S, Rondina MB, Guzzardo V, Parenti AR, Rosato A, Bicciato S, et al. A Mutant-p53/Smad complex opposes p63 to empower TGF $\beta$-induced metastasis. Cell. 2009; 137:87-98.

58. Kalo E, Buganim Y, Shapira KE, Besserglick H, Goldfinger N, Weisz L, Stambolsky P, Henis YI, Rotter V. Mutant p53 attenuates the SMAD-dependent transforming growth factor $\beta 1$ (TGF- $\beta 1$ ) signaling pathway by repressing the expression of TGF- $\beta$ receptor type II. Mol Cell Biol. 2007; 27:8228-42.

59. Sionov RV, Coen S, Goldberg Z, Berger M, Bercovich B, Ben-Neriah Y, Ciechanover A, Haupt Y. c-Abl regulates p53 levels under normal and stress conditions by preventing its nuclear export and ubiquitination. Mol Cell Biol. 2001; 21:5869-78.

60. Chau JF, Jia D, Wang Z, Liu Z, Hu Y, Zhang X, Jia H, Lai KP, Leong WF, Au BJ, Mishina Y, Chen YG, Biondi C, et al. A crucial role for bone morphogenetic protein-Smad1 signalling in the DNA damage response. Nat Commun. 2012; 3:836.

61. Frank-Raue K, Fabel M, Delorme S, Haberkorn U, Raue F. Efficacy of imatinib mesylate in advanced medullary thyroid carcinoma. Eur J Endocrinol. 2007; 157:215-20.

62. Bajaj GK, Zhang Z, Garrett-Mayer E, Drew R, Sinibaldi V, Pili R, Denmeade SR, Carducci MA, Eisenberger MA, DeWeese TL. Phase II study of imatinib mesylate in patients with prostate cancer with evidence of biochemical relapse after definitive radical retropubic prostatectomy or radiotherapy. Urology. 2007; 69:526-31.

63. Lin AM, Rini BI, Derynck MK, Weinberg V, Park M, Ryan CJ, Rosenberg JE, Bubley G, Small EJ. A phase I trial of docetaxel/estramustine/imatinib in patients with hormone-refractory prostate cancer. Clin Genitourin Cancer. 2007; 5:323-8.

64. Lin AM, Rini BI, Weinberg V, Fong K, Ryan CJ, Rosenberg JE, Fong L, Small EJ. A phase II trial of imatinib mesylate in patients with biochemical relapse of prostate cancer after definitive local therapy. BJU Int. 2006; 98:763-9.

65. Wendt MK, Smith JA, Schiemann WP. Transforming growth factor- $\beta$-induced epithelial-mesenchymal transition facilitates epidermal growth factor-dependent breast cancer progression. Oncogene. 2010; 29:6485-98.

66. Arany PR, Flanders KC, Kobayashi T, Kuo CK, Stuelten C, Desai KV, Tuan R, Rennard SI, Roberts AB. Smad3 deficiency alters key structural elements of the extracellular matrix and mechanotransduction of wound closure. Proc Natl Acad Sci USA. 2006; 103:9250-5.

67. Osborne LD, Li GZ, How T, O'Brien ET, Blobe GC, Superfine R, Mythreye K. TGF- $\beta$ regulates LARG, GEF-H1 during EMT to affect stiffening response to force and cell invasion. Mol Biol Cell. 2014; 25:3528-40.

68. Nelson CM, Vanduijn MM, Inman JL, Fletcher DA, Bissell MJ. Tissue geometry determines sites of mammary branching morphogenesis in organotypic cultures. Science. 2006; 314:298-300.

69. Yori JL, Seachrist DD, Johnson E, Lozada KL, AbdulKarim FW, Chodosh LA, Schiemann WP, Keri RA. Kruppel-like factor 4 inhibits tumorigenic progression and metastasis in a mouse model of breast cancer. Neoplasia. 2011; 13:601-10.

70. Rowland BD, Bernards R, Peeper DS. The KLF4 tumour suppressor is a transcriptional repressor of $\mathrm{p} 53$ that acts as a context-dependent oncogene. Nat Cell Biol. 2005; 7:1074-82.

71. Rowland BD, Peeper DS. KLF4, p21 and context-dependent opposing forces in cancer. Nat Rev Cancer. 2006; 6:11-23.

72. Morikawa M, Koinuma D, Mizutani A, Kawasaki N, Holmborn K, Sundqvist A, Tsutsumi S, Watabe T, Aburatani H, Heldin CH, Miyazono K. BMP sustains embryonic stem cell self-renewal through distinct functions of different Kruppellike factors. Stem Cell Reports. 2016; 6:64-73.

73. Scheel C, Eaton EN, Li SH, Chaffer CL, Reinhardt F, Kah KJ, Bell G, Guo W, Rubin J, Richardson AL, Weinberg RA. Paracrine and autocrine signals induce and maintain mesenchymal and stem cell states in the breast. Cell. 2011; 145:926-40.

74. Gao H, Chakraborty G, Lee-Lim AP, Mo Q, Decker M, Vonica A, Shen R, Brogi E, Brivanlou AH, Giancotti FG. The BMP inhibitor Coco reactivates breast cancer cells at lung metastatic sites. Cell. 2012; 150:764-79.

75. Buijs JT, van der Horst G, van den Hoogen C, Cheung H, de Rooij B, Kroon J, Petersen M, van Overveld PG, Pelger RC, van der Pluijm G. The BMP2/7 heterodimer inhibits the human breast cancer stem cell subpopulation and bone metastases formation. Oncogene. 2012; 31:2164-74.

76. Gronroos E, Kingston IJ, Ramachandran A, Randall RA, Vizan P, Hill CS. Transforming growth factor $\beta$ inhibits bone morphogenetic protein-induced transcription through novel phosphorylated Smad1/5-Smad3 complexes. Mol Cell Biol. 2012; 32:2904-16.

77. Kua HY, Liu H, Leong WF, Li L, Jia D, Ma G, Hu Y, Wang X, Chau JF, Chen YG, Mishina Y, Boast S, Yeh J, et al. c-Abl promotes osteoblast expansion by differentially regulating canonical and non-canonical BMP pathways and p16INK4a expression. Nat Cell Biol. 2012; 14:727-37.

78. Ghosh-Choudhury N, Mandal CC, Das F, Ganapathy S, Ahuja S, Ghosh Choudhury G. c-Abl-dependent molecular circuitry involving Smad5 and phosphatidylinositol 3-kinase regulates bone morphogenetic protein-2-induced osteogenesis. J Biol Chem. 2013; 288:24503-17. 
79. Woodring PJ, Hunter T, Wang JY. Inhibition of c-Abl tyrosine kinase activity by filamentous actin. J Biol Chem. 2001; 276:27104-10.

80. Woodring PJ, Hunter T, Wang JY. Regulation of F-actindependent processes by the Abl family of tyrosine kinases. J Cell Sci. 2003; 116:2613-26.

81. Woodring PJ, Litwack ED, O'Leary DD, Lucero GR, Wang JY, Hunter T. Modulation of the F-actin cytoskeleton by c-Abl tyrosine kinase in cell spreading and neurite extension. J Cell Biol. 2002; 156:879-92.

82. Edwards PA, Abram CL, Bradbury JM. Genetic manipulation of mammary epithelium by transplantation. J Mammary Gland Biol Neoplasia. 1996; 1:75-89.

83. Dontu G, Abdallah WM, Foley JM, Jackson KW, Clarke MF, Kawamura MJ, Wicha MS. In vitro propagation and transcriptional profiling of human mammary stem/ progenitor cells. Genes Dev. 2003; 17:1253-70.
84. Zhang X, Claerhout S, Prat A, Dobrolecki LE, Petrovic I, Lai Q, Landis MD, Wiechmann L, Schiff R, Giuliano M, Wong H, Fuqua SW, Contreras A, et al. A renewable tissue resource of phenotypically stable, biologically and ethnically diverse, patient-derived human breast cancer xenograft models. Cancer Res. 2013; 73:4885-97.

85. Galliher AJ, Schiemann WP. Src phosphorylates Tyr284 in TGF- $\beta$ type II receptor and regulates TGF- $\beta$ stimulation of p38 MAPK during breast cancer cell proliferation and invasion. Cancer Res. 2007; 67:3752-8.

86. Galliher AJ, Schiemann WP. $\beta 3$ integrin and Src facilitate transforming growth factor- $\beta$ mediated induction of epithelial-mesenchymal transition in mammary epithelial cells. Breast Cancer Res. 2006; 8:R42. 